\title{
How Observable Is Lithium Plating? Differential Voltage Analysis to Identify and Quantify Lithium Plating Following Fast Charging of Cold Lithium-Ion Batteries
}

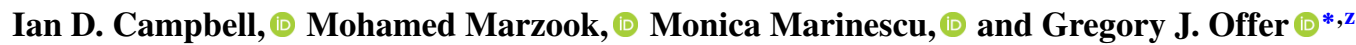 \\ Department of Mechanical Engineering, Imperial College London, South Kensington, London SW7 2AZ, \\ United Kingdom
}

Fast charging of batteries is currently limited, particularly at low temperatures, due to difficulties in understanding lithium plating. Accurate, online quantification of lithium plating increases safety, enables charging at speeds closer to the electrochemical limit and accelerates charge profile development. This work uses different cell cooling strategies to expose how voltage plateaus arising from cell self-heating and concentration gradients during fast charging can falsely indicate plating, contrary to prevalent current assumptions. A solution is provided using Differential Voltage (DV) analysis, which confirms that lithium stripping is observable. However, scanning electron microscopy and energy-dispersive X-ray analysis are used to demonstrate the inability of the plateau technique to detect plating under certain conditions. The work highlights error in conventional plating quantification that leads to the dangerous underestimation of plated amounts. A novel method of using voltage plateau end-point gradients is proposed to extend the sensitivity of the technique, enabling measurement of lower levels of lithium stripping and plating. The results are especially relevant to automotive OEMs and engineers wishing to expand their online and offline tools for fast charging algorithm development, charge management and state-of-health diagnostics.

(C) The Author(s) 2019. Published by ECS. This is an open access article distributed under the terms of the Creative Commons Attribution 4.0 License (CC BY, http://creativecommons.org/licenses/by/4.0/), which permits unrestricted reuse of the work in any medium, provided the original work is properly cited. [DOI: $10.1149 / 2.0821904$ jes]

(cc) BY

Manuscript submitted December 28, 2018; revised manuscript received February 17, 2019. Published March 6, 2019.

Fast charging of lithium-ion batteries remains a priority amongst automotive Original Equipment Manufacturers (OEMs) that are electrifying their product portfolios. Consequently, there are increasingly large demands on time and monetary investment in the development of fast charging strategies, for which, the avoidance of lithium plating is a priority. However, the techniques available for inexpensive, nondestructive and fast plating identification and quantification are immature and contribute to the cost of development. Moreover, increased accuracy of plating assessments is required for improved online, Battery Management System (BMS)-based diagnostics and charge strategy de-rating. Researchers also demand alternatives to destructive evaluation techniques. The instability of $\mathrm{Li}^{0}$ coupled with the timeframe between plating and cell disassemly presents a major problem because ex-situ observations may no longer be accurate. ${ }^{1}$

During charging of a lithium-ion cell with a graphitic Negative Electrode (NE) the reversible lithium intercalation reaction proceeds in the reduction direction according to Equation 1 at the NE. Under certain conditions, overpotential exceeding NE equilibrium potential or $\mathrm{Li}$ concentration saturation of the graphite, the competing lithium metal deposition reaction additionally proceeds. It does so in the reduction direction according to Equation 2, inducing lithium plating (deposition).

$$
\begin{gathered}
\mathrm{Li}_{x} \mathrm{C}_{6} \underset{\text { reduction }}{\stackrel{\text { oxidation }}{\rightleftarrows}} x \mathrm{Li}^{+}+x \mathrm{e}^{-}+6 \mathrm{C} \\
\mathrm{Li}^{0} \underset{\text { reduction }}{\stackrel{\text { oxidation }}{\rightleftarrows}}(1-x) \mathrm{Li}^{+}+(1-x) \mathrm{e}^{-}
\end{gathered}
$$

Since both reactions are reversible, cell discharging oxidizes lithium sourced from both reactants, $\mathrm{Li}_{x} \mathrm{C}_{6}$ and $\mathrm{Li}^{0}$. Versus $\mathrm{Li}_{x} \mathrm{C}_{6}$ oxidation, the relatively facile $\mathrm{Li}^{0}$ oxidation (stripping) process and associated lower oxidation potential produce a high voltage discharge plateau. ${ }^{2,3}$ The plateau has traditionally been used to identify $\mathrm{Li}^{0}$ stripping, and by extension, lithium plating. ${ }^{4-7}$ Extensions of those works report the discharge plateau measurement as a technique for the semiquantitative assessment of lithium plating. ${ }^{2,8}$ Petzl \& Danzer further reported the technique as fully quantitative, employing differential voltage analysis for unambiguous determination of plateau length. ${ }^{9,10}$

\footnotetext{
*Electrochemical Society Member.
}

${ }^{\text {z } E-m a i l: ~ g r e g o r y . o f f e r @ i m p e r i a l . a c . u k ~}$
In this work, the phrase "the technique" is used to refer to the practice of using the high voltage plateau to identify and/or quantify lithium plating and stripping. Throughout the technique's evolution from a qualitative to a quantitative tool, few works have addressed its accuracy and reliability or considered in full the difference between quantifying stripping and quantifying plating. ${ }^{11}$

Moreover, the use of the technique for lithium plating identification alone is still not fully understood and is without consensus. The traditional belief that an absence of a plateau is indicative of an absence of plating ${ }^{2,5}$ has been challenged, but remains unclear. The concern by Smart et al. ${ }^{5}$ that Chemical Intercalation (CI) could result in a reduction or absence of $\mathrm{Li}^{0}$ availability, and consequently the absence of a stripping plateau in spite of plating having occurred, has been reiterated. $^{12-15}$ It has been suggested that the stripping current is dependent upon the areal coverage of lithium ${ }^{16}$ and additionally, that the area be of a minimum size for detection. ${ }^{11,14}$ Following plating, the interplay between CI, stripping and irreversible Loss of Lithium Inventory (LLI) owing to parasitic reaction is acknowledged as complex, and requires further studies to develop the state of knowledge.

The technique has been nearly universally developed and studied i) under the conditions of slow charging where cell self-heating is insubstantial and with cell temperature deviating little spatially and versus the ambient, and additionally, where solid-phase lithium concentration gradients are small, or ii) at ambient temperatures so low that they are rarely applicable to Electric Vehicles (EVs). This development history has led to perpetuation of the theory that the technique functions only at temperatures of $-20^{\circ} \mathrm{C}$ and below. ${ }^{13,14,16}$ However, the discharge plateau technique's performance is arguably of greatest interest to the automotive sector following fast charging, when the propensity to lithium plate is greater than following slow charging, and at temperatures more commonly encountered by EVs. A dearth of information exists under these conditions, as Table I demonstrates.

The majority of works given in Table I report only ambient temperatures and neglect the difference relative to cell temperature. Uhlmann, Illig, Ender, Schuster \& Ivers-Tiffée investigated plating following $10 \mathrm{C}$ charge pulses at $23^{\circ} \mathrm{C}$, but via the alternative relaxation technique. ${ }^{16}$ While works such as that by Tippmann, Walper, Balboa, Spier \& Bessler have simulated the influence of cell self-heating on NE potential during charging, few have done so with a focus on the high voltage plateau. ${ }^{11,17}$ Yang, Ge, Liu, Leng, \& Wang probed via simulation the influence of temperature on the voltage curves, again during relaxation, for the same quantity of $\mathrm{Li}^{0} .{ }^{11}$ Similarly, little attention has been afforded to the influence of instantaneous State of Charge (iSOC) 


\section{Table I. Summary of charge rates and ambient temperatures, $T_{\mathrm{amb}}$, during application \& study of the discharge plateau technique in literature.}

\begin{tabular}{|c|c|c|c|}
\hline Work & $\begin{array}{c}\text { Max. rate } \\
\text { (Low } T_{\mathrm{amb}} \text { ) }\end{array}$ & $T_{\mathrm{amb}},\left({ }^{\circ} \mathrm{C}\right)$ & Pub. \\
\hline Smart et al. ${ }^{4}$ & $\frac{1}{8} \mathrm{C}$ & $-40,-20,23$ & 2002 \\
\hline Smart et al. ${ }^{5}$ & $\frac{1}{3} \mathrm{C}$ & $-40,-20,0,23$ & 2003 \\
\hline Fan $\& \operatorname{Tan}^{6}$ & $\frac{1}{1.25} \mathrm{C}$ & $-30,-20, \mathrm{RT}^{\mathrm{a}}$ & 2006 \\
\hline Smart \& Ratnakumar ${ }^{2}$ & $\frac{1}{5.7} \mathrm{C}$ & $-40,-30,-20,25$ & 2011 \\
\hline Zinth et al. ${ }^{1}$ & $\frac{1}{5} \mathrm{C}$ & -20 & 2014 \\
\hline Petzl \& Danzer ${ }^{9}$ & $1 \mathrm{C}$ & $-26,-24,-22,-20$ & 2014 \\
\hline \multicolumn{4}{|l|}{ Danzer, Bauer, } \\
\hline Schindler \& Petzl ${ }^{10}$ & $1 \mathrm{C}$ & $-20,25$ & 2016 \\
\hline Waldmann et al. ${ }^{29}$ & $\frac{1}{2} \mathrm{C}$ & $0,5,25,45$ & 2017 \\
\hline Waldmann \& W-Mehrens ${ }^{15}$ & $\frac{1}{2} \mathrm{C}$ & 0 & 2017 \\
\hline Kowal et al. ${ }^{33}$ & $3 \mathrm{C}$ & $-20,-10,0$ & 2018 \\
\hline Yang et al. ${ }^{11}$ & $5 \mathrm{C}$ & 0 & 2018 \\
\hline Ren et al. ${ }^{35}$ & $2 \mathrm{C}$ & -5 & 2018 \\
\hline
\end{tabular}

${ }^{\mathrm{a}} \mathrm{RT}$ refers to Room Temperature, where authors did not specify a value.

on the technique's performance. Recently, it has been reported that without a reference electrode, plating detection via differential voltage analysis is possible only when the Positive Electrode (PE) contributes negligibly to the cell potential profile, such as with the use of $\mathrm{LiFePO}_{4}{ }^{9}{ }^{9}$ This is in spite of the existence of works to the contrary demonstrating successful use of the technique with mesocarbon microbead-Nickel Cobalt (NC) ${ }^{2}$ and graphite-Nickel Manganese Cobalt (NMC) $)^{11}$ cells.

In this work, we investigate the technique's characteristics in light of high charge rates - up to $9.1 \mathrm{~mA} . \mathrm{cm}^{-2}$, equivalent to $5.0 \mathrm{C}$ - at $0^{\circ} \mathrm{C}$. In doing so, we highlight issues with the voltage plateau for plating identification in the presence of high cell temperatures and steep solid phase concentration gradients associated with fast charging. The results indicate that the technique is applicable at temperatures far above $-20^{\circ} \mathrm{C}$, thereby resolving suggestions to the contrary. We demonstrate conclusively through the use of a graphite-NC cell chemistry that even where the differential voltage signature is a composite of two complex individual electrode potentials, both plating detection and quantification are possible with the voltage plateau technique in commercial cells. We discuss important considerations related to the accuracy of the technique that we believe remain under-addressed following its

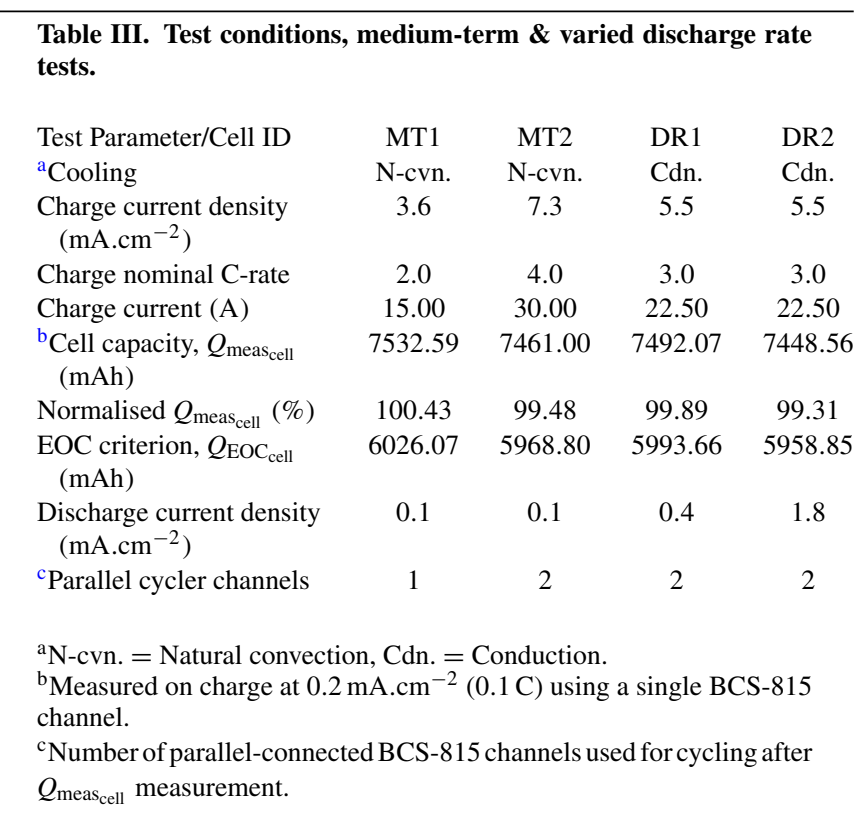

evolution from qualitative indicator to quantitative tool; namely the underestimation of plating by neglecting $\mathrm{CI}$ of $\mathrm{Li}^{0}$ during the charge process. The results provide strong evidence in support of the theory that the absence of a high voltage plateau is not indicative of an absence of plating. Furthermore, we probe increased discharge rates as a strategy for increasing the practicality of the technique and study their influence on the accuracy of plating estimates. Finally, we propose and demonstrate a method for increasing the sensitivity of the technique for quantification, extending the scope of its use.

\section{Experimental}

17 commercial cells were fast charged under a combination of different rates, cooling scenarios and cycle counts. Tables II and III summarize the experimental details. All testing was performed on commercially available high energy Kokam 7.5 Ah $\left(Q_{\text {nom }}\right)$ cells with model number SLPB75106100. All cells were drawn from the same batch and exhibited a standard deviation between normalized charge capacities of $<0.9 \%$. Although nominally NMC-graphite, Inductively Coupled Plasma Optical Emission Spectroscopy (ICP-OES) has shown that the $\mathrm{PE}$ is rather $\mathrm{LiNi}_{0.4} \mathrm{Co}_{0.6} \mathrm{O}_{2}$. Moreover, the $\mathrm{NE}$ is reportedly $4.4 \%$ larger in surface area than the positive. The maximum

Table II. Test conditions, short-term tests with $0.1 \mathrm{~mA} . \mathrm{cm}^{-2}$ discharging.

\begin{tabular}{|c|c|c|c|c|c|c|c|c|c|c|c|c|c|}
\hline Test Parameter/Cell ID & A & B & $\mathrm{C}$ & $\mathrm{D}$ & $\mathrm{E}$ & $\mathrm{F}$ & G & $\mathrm{H}$ & I & $\mathbf{J}$ & K & $\mathrm{L}$ & M \\
\hline${ }^{\mathrm{a} C}$ Cooling & N-cvn. & $\mathrm{N}$-cvn. & N-cvn. & N-cvn. & Cdn. & Cdn. & Cdn. & Cdn. & Cdn. & Cdn. & Cdn. & Cdn. & Cdn. \\
\hline Charge current (A) & 11.25 & 15.00 & 22.50 & 30.00 & 7.50 & 11.25 & 15.00 & 18.75 & 22.50 & 26.25 & 30.00 & 33.75 & 37.50 \\
\hline $\begin{array}{l}{ }^{\mathrm{b}} \text { Cell capacity, } Q_{\text {meas }} \text { cell } \\
\text { (mAh) }\end{array}$ & 7460.61 & 7526.66 & 7691.6 & 7629.17 & 7452.57 & 7457.02 & 7465.89 & 7458.22 & 7465.53 & 7474.49 & 7445.89 & 7468.83 & 7495.42 \\
\hline Normalised $Q_{\text {meas }_{\text {cell }}}(\%)$ & 99.47 & 100.36 & 102.55 & 101.72 & 99.37 & 99.43 & 99.55 & 99.44 & 99.54 & 99.66 & 99.28 & 99.58 & 99.94 \\
\hline${ }^{\mathrm{c}}$ Parallel cycler channels & 1 & 1 & 2 & 2 & 1 & 1 & 1 & 2 & 2 & 2 & 2 & 3 & 3 \\
\hline
\end{tabular}




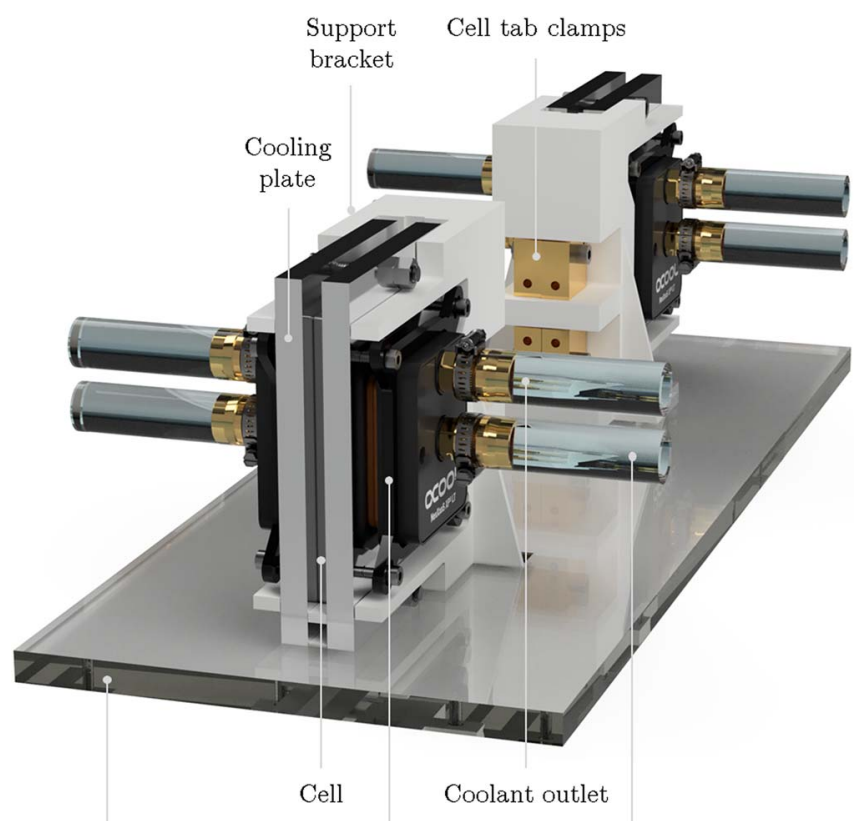

Support base Water block Coolant inlet

Figure 1. Rendering of the pair of cooling rigs used for conduction cooling tests.

manufacturer-recommended charge rate is $1.8 \mathrm{~mA} . \mathrm{cm}^{-2}(1.0 \mathrm{C})$ in the range $0^{\circ} \mathrm{C}$ to $40^{\circ} \mathrm{C}$, whilst lower $\left(V_{\min }\right)$ and upper $\left(V_{\max }\right)$ cutoff voltages are $2.7 \mathrm{~V}$ and $4.2 \mathrm{~V}$, respectively. ${ }^{18}$

Testing was conducted under two thermal scenarios, natural air convection and conduction. For the natural convection tests, cells were cycled in an incubator (BINDER, KB 23) with a set point of $0^{\circ} \mathrm{C}$. A fan speed of $100 \%$ was required to reach the set point, but all cells were enclosed in plastic containers to maintain static ambient air. Short term cell tests under natural convection conditions involved the following fast charge rates: $2.7 \mathrm{~mA} . \mathrm{cm}^{-2}(1.5 \mathrm{C}), 3.6 \mathrm{~mA} . \mathrm{cm}^{-2}(2.0 \mathrm{C})$, $5.5 \mathrm{~mA} . \mathrm{cm}^{-2}(3.0 \mathrm{C})$ and $7.3 \mathrm{~mA} . \mathrm{cm}^{-2}$ (4.0 C). All C-rates were calculated using nominal cell capacity. Three type K thermocouples (TCs) (accuracy $\pm 1.5^{\circ} \mathrm{C}$ ) were adhered to one face of each cell; one adjacent to the tabs, one at the geometric center and another at the corner opposite the tabs. Temperature closest to the tabs was recorded using the battery cycler, while temperatures at all other locations, including a fourth TC measuring ambient (incubator) temperature, were recorded using a data logger (Pico Technology, TC-08).

For the conduction tests, cells were cycled in the custom cooling rigs illustrated in Figure 1. Thermal paste with a conductivity of $5 \mathrm{~W} \cdot \mathrm{m}^{-1} \cdot \mathrm{K}^{-1}$ was applied to both faces of the cells before they were clamped at $20 \%$ State of Charge (SOC) between aluminum cooling plates by torquing clamping bolts to $1 \mathrm{Nm}$. This resulted in a cell facial pressure of $0.14 \mathrm{MPa}$ that has been demonstrated to not significantly influence electrochemical behavior. ${ }^{19}$ A water/propylene glycol (1:1) coolant was maintained at a set point of $0^{\circ} \mathrm{C}$ and circulated with $100 \%$ pump speed using a refrigerated bath circulator (Thermo Fisher Scientific, ARCTIC PC200-A25) through water blocks plumbed in parallel. Hence, the cooling plates were in turn cooled by forced convection. The rigs were contained within a temperature chamber (ESPEC, BPL3 ) with a set point of $0^{\circ} \mathrm{C}$. Short term cell tests under conduction conditions involved fast charge rates from $1.8 \mathrm{~mA} . \mathrm{cm}^{-2}$ to $9.1 \mathrm{~mA} . \mathrm{cm}^{-2}$ $(1.0 \mathrm{C}$ to $5.0 \mathrm{C})$ in $0.9 \mathrm{~mA} . \mathrm{cm}^{-2}(0.5 \mathrm{C})$ increments. Type-K TCs were again used; one on the sidewall containing the tabs and another on the opposite side wall.

All charge-discharge cycling was conducted using a battery cycler (Bio-Logic, BCS-815) where cell tab contact resistances had been minimized with tightly-clamped, polished brass tab clamps. Each test was conducted on a pristine cell to eliminate the influence of any prior plating. With the exception of the different fast charge rates, all cells were subjected to identical cycling since history is known to influence the discharge voltage profile. ${ }^{6}$ All charging was via a Constant Current Constant Voltage (CCCV) strategy, in spite of the alternatives that exist, because of its widespread usage. Prior to beginning cycling, all cells were allowed a minimum of 10 hours to thermally equilibrate at the set point. Cells were initially discharged at $0.4 \mathrm{~mA} . \mathrm{cm}^{-2}(\mathrm{C} / 5)$ to $V_{\min }$, allowed 1 hour to equilibrate, then charged $\left(0.2 \mathrm{~mA} \cdot \mathrm{cm}^{-2}\right.$ (C/10) Constant Current (CC), Constant Voltage (CV) until current $\left.I<0.1 \mathrm{~mA} \cdot \mathrm{cm}^{-2}(\mathrm{C} / 20)\right)$ to evaluate capacity, $Q$. Following $Q$ evaluation, all charges were from $0 \%$ to $80 \%$ SOC, in-line with current Society of Automotive Engineers (SAE) Level 3 fast charging standards for Battery Electric Vehicles (BEVs). ${ }^{20}$ Moreover, end-of-charge was determined via coulomb counting and end-of-discharge by terminal voltage cutoff. Cells were recharged at a reference rate of $0.2 \mathrm{~mA} . \mathrm{cm}^{-2}$ (the "reference charge") and immediately discharged at $0.1 \mathrm{~mA} \cdot \mathrm{cm}^{-2}$ to $V_{\min }$ (the "reference discharge"). Following 1 hour of equilibration, cells were recharged at one of the fast charging rates given above and again immediately discharged at $0.1 \mathrm{~mA} . \mathrm{cm}^{-2}$ to $V_{\min }$. For the avoidance of doubt, immediate discharge following reference or fast charging was used to avoid any relaxation time at this stage. This is desirable to minimize $\mathrm{CI}$ and to investigate the voltage plateau technique's performance under practically-relevant conditions where time for cell equilibration is often unavailable.

Two additional cells were charged following the above procedure under conduction conditions at $5.5 \mathrm{~mA} . \mathrm{cm}^{-2}$, but were discharged at the higher rates of $0.4 \mathrm{~mA} . \mathrm{cm}^{-2}$ and $1.8 \mathrm{~mA} . \mathrm{cm}^{-2}$ to investigate the effect of accelerating detection. A further two cells, referred to as MT1 and MT2, underwent medium term cycling under natural convection conditions to investigate the technique's detection sensitivity. The cells were subjected to consecutive fast charging at $3.6 \mathrm{~mA} . \mathrm{cm}^{-2}$ (63 complete cycles) and $7.3 \mathrm{~mA} \cdot \mathrm{cm}^{-2}$ (64 complete cycles) with each discharge at $0.1 \mathrm{~mA} . \mathrm{cm}^{-2}$ followed by 1 hour of rest.

With the exception of the two cells which underwent medium term cycling, the following sampling frequencies, $f_{\mathrm{s}}$, were used: reference $0.2 \mathrm{~mA} . \mathrm{cm}^{-2}$ charging at $1 \mathrm{~Hz}$; reference $0.1 \mathrm{~mA} . \mathrm{cm}^{-2}$ discharging, fast charging, and $0.1 \mathrm{~mA} . \mathrm{cm}^{-2}$ discharging following fast charging all at $10 \mathrm{~Hz}$. The same $f_{\mathrm{s}}$ settings were used for the initial 13 (cell MT1) and 14 (cell MT2) complete cycles in medium term testing. However, owing to battery cycler limitations, the sampling rate was reduced and all phases of the remaining cell MT1 and MT2 cycles were recorded at $1 \mathrm{~Hz}$. Owing to the noise associated with the data acquisition, post-processing was necessary and the parameters are provided here for reproducibility. All temperature data was smoothed with parameters $\{$ method, window, iterations $\}=\{$ moving average $, 0.5 \%, 2\}$. When used for differential voltage analysis, voltage data was smoothed with the same parameters. All derivatives were computed by forward finite differencing except for $Q \mathrm{~d}^{2} V \mathrm{~d} Q^{-2}$ which was computed by differentiating a tenth-degree fitted polynomial to accommodate noise remaining in the smoothed $Q \mathrm{~d} V \mathrm{~d} Q^{-1}$ data.

Along with a pristine cell, those two cells which underwent medium-term cycling were subsequently discharged to $V_{\min }$ and disassembled in a fume hood. Their NE surface morphologies and material compositions were investigated using a combination of scanning electron microscopy (Thermo Scientific Phenom ProX) and EnergyDispersive X-ray (EDX) analysis. Scanning Electron Microscope (SEM) imaging was conducted with a magnification of 500 times and an acceleration voltage of $10 \mathrm{kV}$.

\section{Results and Discussion}

Reliable plating identification despite self-heating and concentration gradients.-Fast charging typically involves high current densities which in turn induce large overpotentials. Heat generation via cell polarization in particular is then large, resulting in a rapid rise in cell temperature relative to the ambient and a reduction in cell impedance. Cell potential, current density and temperature data during charging is provided in the Supplementary Material. The highest cell surface temperature reached at the beginning of discharge 

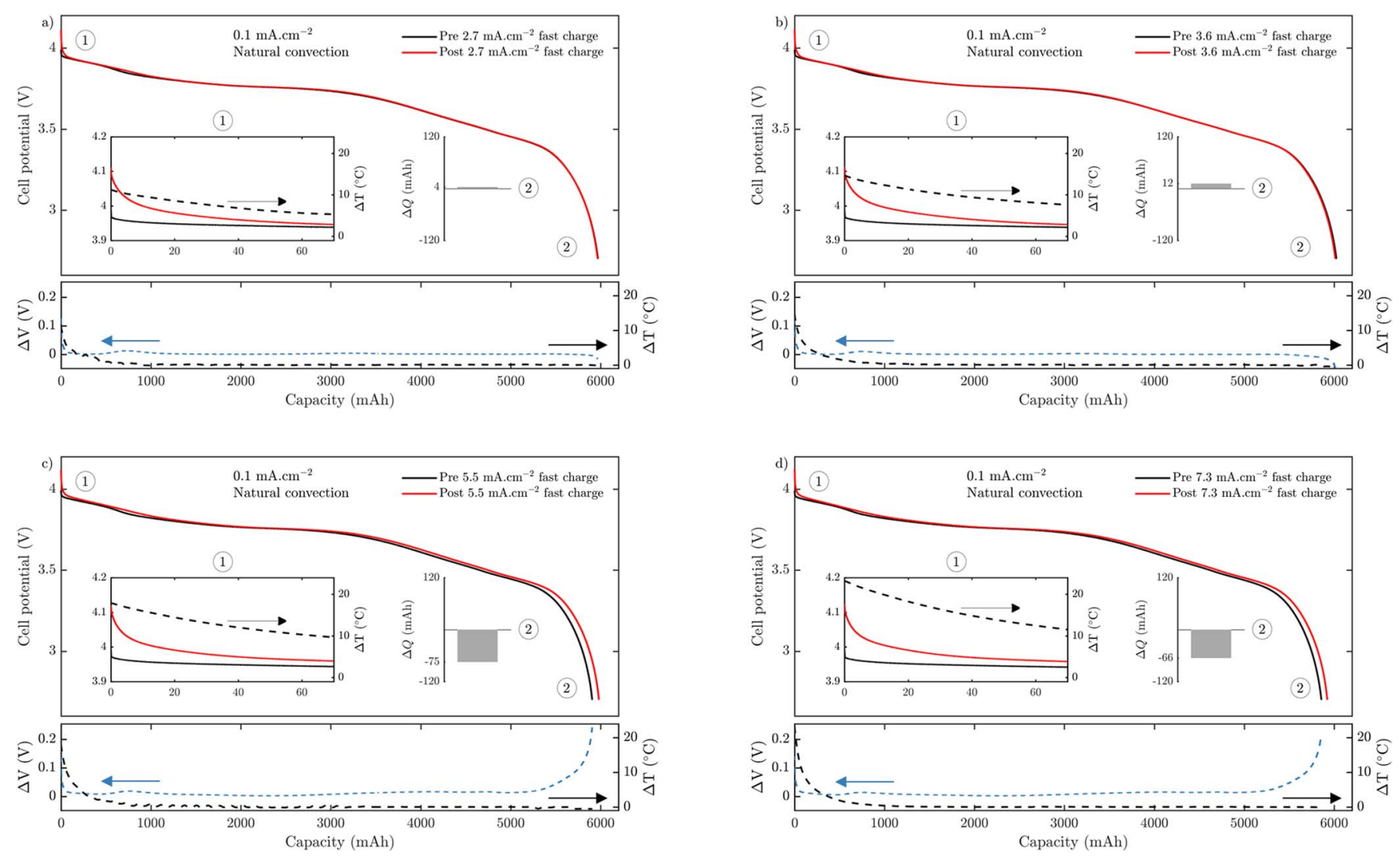

Figure 2. Cell potential under galvanostatic discharge and a natural convection Boundary Condition (BC). Black curves represent discharge following $0.2 \mathrm{~mA} . \mathrm{cm}^{-2}$ charge, red curves represent discharge following fast charging at the current densities in each figure quadrant. In each quadrant, left insets show a magnified window at the beginning of discharge. Right insets show the difference in measured discharge capacity pre and post-fast charge. Ambient air temperature was $0{ }^{\circ} \mathrm{C}$. $\Delta T$ and $\Delta V$ are are the difference in cell temperature and voltage respectively between the two discharges.

under natural air convection was $23.1^{\circ} \mathrm{C}$, immediately following $7.3 \mathrm{~mA} . \mathrm{cm}^{-2}$ charging. The high magnitude of the rise is due to a combination of high current density, diminished conductivities at this low ambient temperature and a low rate of heat transfer to the surroundings. Black dashed curves at the bottom of all quadrants in Figures 2 and 3 illustrate the difference in cell temperature between reference and post-fast charge discharges. Additionally, fast charging induces large lithium concentration gradients in the electrode particle radial dimension. Consequently, faster charging results in a divergence of iSOC of the cell from average SOC (hereafter referred to as SOC), which contributes to the perception of a high voltage plateau.

$$
z_{\mathrm{i}}=\frac{\frac{c_{\mathrm{s}}^{*}}{c_{\mathrm{s}, \max }}-\theta_{0}}{\theta_{100}-\theta_{0}}
$$

where $c_{\mathrm{s}}^{*}$ is the molar concentration of lithium at the particle surface, $c_{\mathrm{s}, \max }$ is the maximum possible lithium concentration, $\theta_{0}$ and $\theta_{100}$ are the electrode stoichiometries at $0 \%$ and $100 \%$ SOC respectively and $z_{\mathrm{i}}$ is iSOC.

Both of these charge characteristics - increased temperature and iSOC - manifest early in all of the post-fast charge cell potential curves of Figures 2 and 3 as a period of increased cell potential (red curves) relative to the reference discharges (black curves). The iSOC difference contributes only to the immediate difference in cell potential vs. the reference at the beginning of discharge because the surface concentration falls immediately. The temperature effect contributes for longer, especially because inner layers cool more slowly than the surface measurement indicates, but $\Delta T$ is observed to always asymptote to $0^{\circ} \mathrm{C}$ within the initial $1000 \mathrm{mAh}$ of discharge. As the discharge progresses further and the cells which underwent fast charging have cooled, $\frac{d c_{\mathrm{s}}}{d r}$ becomes relaxed and the post-fast charge poten- tials converge to the reference discharge potentials. This total convergence period can be lengthy, sometimes taking place over as much as $\sim 1500 \mathrm{mAh}$ of discharge capacity (see Figure 4a for conduction cooling). The length of this convergence period produces a feature similar to a second plateau at $\sim 750 \mathrm{mAh}$ into the discharges. The difference in durations is greatest for the conductively cooled cells where $\Delta T$ is forced to $0^{\circ} \mathrm{C}$ quickly and the low temperature slows solid-phase $\mathrm{Li}$ diffusion.

On the basis of the terminal voltage profiles alone, it is unclear whether the cause of the increased cell potential is a combined increase in cell temperature and iSOC, a potential plateau resulting from a mixed potential with $\mathrm{Li}^{0}$ stripping, or both. The similar effects of temperature, $\frac{d c_{\mathrm{s}}}{d r}$ variation and $\mathrm{Li}^{0}$ stripping therefore present a challenge for the programmatic, a posteriori identification of plating on an EV BMS. The ambiguity is dangerous for two reasons. Firstly, a plated cell could be misidentified as a warm cell or a cell with iSOC $\gg$ SOC, constituting a false negative diagnostic result and possibly dangerous continued use of the cell or EV. Secondly, the increased potential from lower impedance or high $c_{\mathrm{s}}^{*}$ could be mistaken for a lithium stripping plateau when no plating has occurred, constituting a false positive diagnostic result and possibly leading to premature cell replacement and additional cost.

Figure 3 presents results for the conduction cooling strategy only. Here, the highest cell surface temperature reached at the beginning of discharge was $0.3^{\circ} \mathrm{C}$, immediately following $2.7 \mathrm{~mA} . \mathrm{cm}^{-2}$ charging. The variation across all four fast charging rates was, at less than $0.2^{\circ} \mathrm{C}$, well within measurement error and just $1.3 \%$ of the variation observed across convection tests. Moreover, post-fast charge discharge curves in Figures 2 and 3 are visually indistinguishable from each other, indicating that the raised cell potential curve feature occurs independently of the cell cooling strategy. 

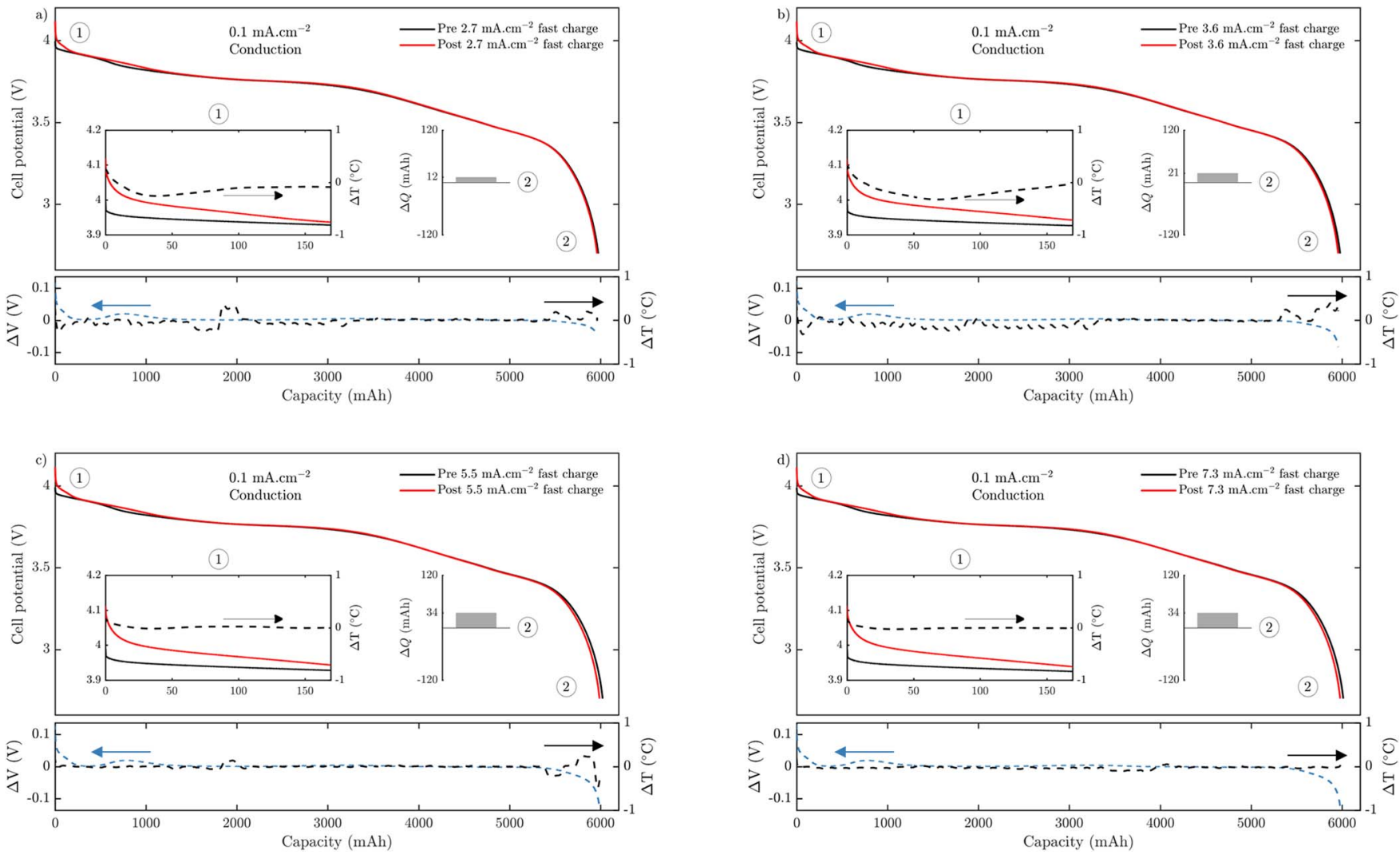

Figure 3. Cell potential under galvanostatic discharge and a conduction BC. Black curves represent discharge following $0.2 \mathrm{~mA} . \mathrm{cm}^{-2}$ charge, red curves represent discharge following fast charging at the current densities in each figure quadrant. Left insets show a magnified window at the beginning of discharge. Right insets show the difference in measured discharge capacity pre and post-fast charge. Ambient air temperature was $0{ }^{\circ} \mathrm{C} . \Delta T$ and $\Delta V$ are are the difference in cell temperature and voltage respectively between the two discharges—note the different $T$ scale vs. Figure 2.

The corresponding DV traces of Figures 4 a (cooling via conduction) and $4 \mathrm{~b}$ (cooling via natural convection) can decouple the influence of heightened cell temperature and $\frac{d c_{\mathrm{s}}}{d r}$ inhomogeneity from the influence of plating, removing the ambiguity in identification. In DV analysis, inflections represent regions of relatively quick potential change for a given change in capacity. Therefore, troughs can be used to identify phase transitions (staging) in the electrode materials. Invariance in DV curves arises from potential plateaus across a capacity window and can therefore be used to identify two-phase coexistence. $\mathrm{d} V \mathrm{~d} Q^{-1}$ data is in all cases normalized by multiplying it by the measured capacity of that cell. This normalization facilitates comparisons with cells of different capacities, such as those tested in other works. Since all full-cell curves represent $0.1 \mathrm{~mA} . \mathrm{cm}^{-2}$ discharge, no ohmic loss (IR) correction is required for comparison between full-cell curves. In Figure 4b, during the initial 300 mAh (inset) of discharge no new inflection corresponding to a plateau end-point following fast charging at any of the four rates was observed. This is especially evident when comparing to the black reference curves. The result does not indicate the prior occurrence of plating and suggests that the terminal voltage deviation for these four cells is solely induced by thermal means and $c_{\mathrm{s}}$ gradients. The validity of correlating plateau absence with plating absence is however explored later.

In contrast, in Figure 4a, the same magnified discharge window (inset) illustrates new DV inflections during discharge for cells which were fast charged at the four high rates and conductively cooled. Hence, the differential signatures indicate the presence of stripping plateaus, and by deduction, the prior occurrence of plating with all four fast charge rates. The cell's propensity to undergo lithium plating appears, as expected, to be sensitive to the aggressiveness of the cooling strategy. The thermal mass provided by the cooling plates and water blocks may also have contributed to a delayed cell temperature rise and increased plating. Crucially, the ambiguity of interpreting the cell potential profile is avoided with identification of plating by DV analysis. We therefore advocate its use not only for the quantification of plating, explored later, but also for its reliable identification under a wider set of circumstances than are possible by studying terminal voltage curves alone. This is especially so for programmatic use, where unambiguous and hence autonomous detection is facilitated only by use of the DV method. For completeness, the Incremental Capacity Analysis (ICA) method provides a similar identification benefit to the DV method. However, the DV method makes for easier graphical interpretation of reversible and irreversible $\mathrm{Li}^{0}$ quantities.

To i) better understand the similarity between the discharge voltage curves across both cooling scenarios, ii) better understand the extent to which internal layer (core) temperatures may be contributing to the voltage plateau-like features, and iii) probe the reason for the ineffectiveness of the voltage curve identification method, we examine the relative rates of heat transfer from and within the cell with a Biot number analysis.

$$
\begin{aligned}
\mathrm{Bi}_{\mathrm{cdn}} & =\frac{U_{\text {cdn }} L_{\mathrm{c}_{\mathrm{cdn}}}}{\bar{k}_{\mathrm{cell}}} \\
& =31.21 \times 10^{-3}<0.1 \\
& \therefore \nabla T \text { is small } \\
\mathrm{Bi}_{\mathrm{cvn}} & =\frac{h_{\mathrm{cvn}} L_{\mathrm{c}_{\mathrm{cvn}}}}{\bar{k}_{\mathrm{cell}}} \\
& =2.59 \times 10^{-3} \ll 0.1 \\
& \therefore \nabla T \text { is small }
\end{aligned}
$$



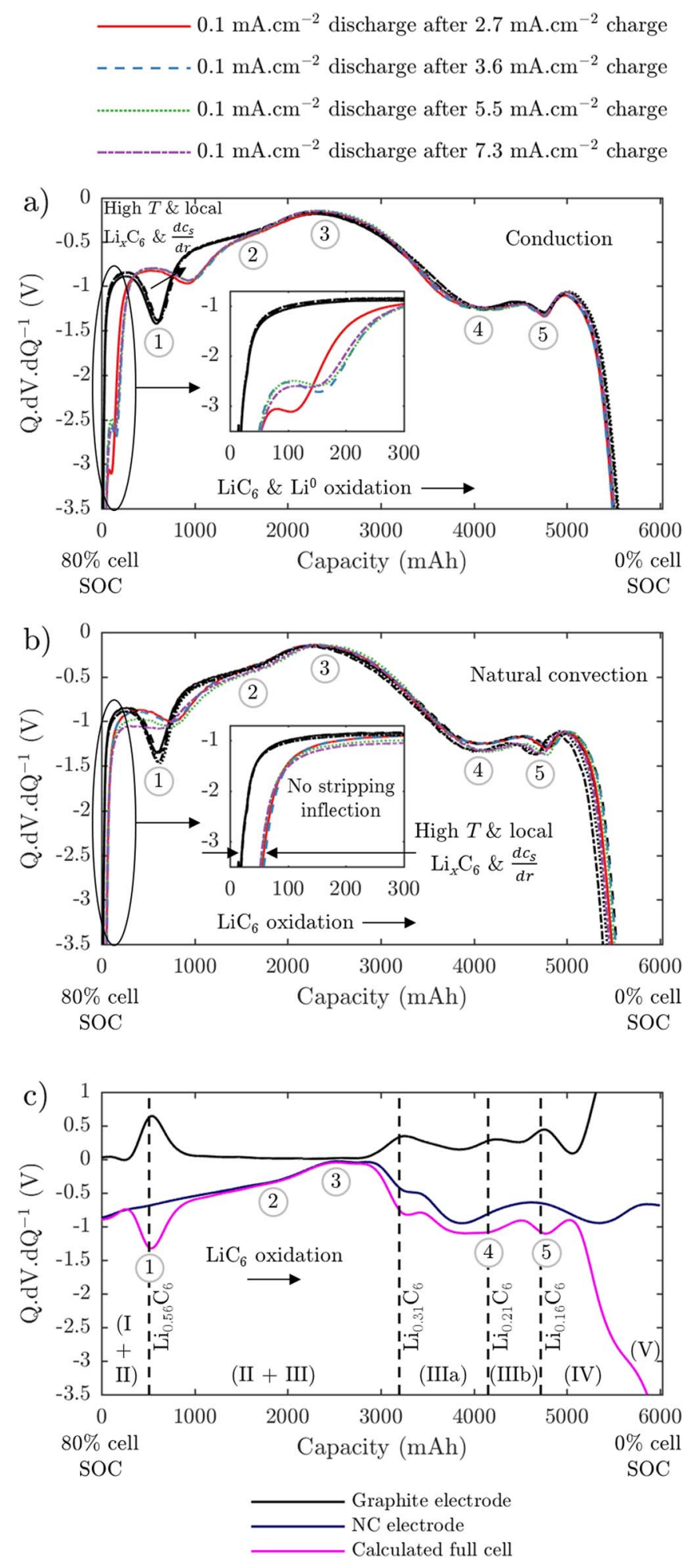

Figure 4. a) Differential full-cell potential corresponding to discharges in Figure 3. Black curves are reference discharges, prior to any fast charging. b) Differential full-cell potential corresponding to discharges in Figure 2. Black curves are reference discharges, prior to fast charging. c) Differential half-cell pseudo open-circuit potentials vs. $\mathrm{Li} / \mathrm{Li}^{+}$measured at $23^{\circ} \mathrm{C}$ during half-cell charging. ${ }^{18}$ Pink curve is the calculated and normalized full-cell $Q \mathrm{~d} V \mathrm{~d} Q^{-1}$ profile. where $\mathrm{Bi}_{\mathrm{cdn}}$ and $\mathrm{Bi}_{\mathrm{cvn}}$ denote the Biot numbers, $U_{\mathrm{cdn}}$ $\left(529.0 \mathrm{~W} \cdot \mathrm{m}^{-2} \cdot \mathrm{K}^{-1}\right)$ and $h_{\mathrm{cvn}}\left(6.6 \mathrm{~W} \cdot \mathrm{m}^{-2} \cdot \mathrm{K}^{-1}\right)$ the heat transfer coefficients, and $L_{\mathrm{ccdn}}\left(3.95 \times 10^{-3} \mathrm{~m}\right)$ and $L_{\mathrm{ccvn}}\left(26.11 \times 10^{-3} \mathrm{~m}\right)$ the characteristic lengths in the conduction and convection cooling scenarios, respectively. $\bar{k}_{\text {cell }}\left(66.95 \mathrm{~W} \cdot \mathrm{m}^{-1} \cdot \mathrm{K}^{-1}\right)$ is the mass-averaged lumped cell thermal conductivity.

Surface and average cell temperatures in the conduction scenario are lower in magnitude and variability relative to the convection scenario. However, the relative value of the conduction Biot number $\left(31.21 \times 10^{-3}\right.$ vs. $2.59 \times 10^{-3}$ for convection) suggests the presence of steeper thermal gradients for cells experiencing conduction. This is reasonable. Nonetheless, the absolute values of both Biot numbers, at less than 0.1 , suggest that internal cell temperatures are within $5 \%$ of each other. ${ }^{21}$ That is, by conventional thermal engineering standards, thermal gradients can in both scenarios be considered insignificant.

However, Biot numbers less than 0.1 may not be enough to discount the influence of even slightly elevated core temperatures on the terminal voltage, owing to the lithium-ion battery's extreme temperature sensitivity. We expect that core temperatures at the beginning of discharges, prior to long slow discharge (cooling) periods, will certainly be influencing the discharge voltage profile. That is in spite of the internal temperature gradients being small. In conclusion, identification of lithium stripping plateaus is difficult because $c_{\mathrm{s}}$ gradients exist, but also because even slightly elevated core temperatures have a meaningful effect on the terminal voltage. Moreover, the results highlight that the influence of $\mathrm{Li}^{0}$ oxidation on the terminal voltage cannot be isolated in the voltage curve with an attempt to use aggressive cell cooling to attenuate the influence of temperature. Future experiments with single-layer cells, providing improved control of thermal gradients, are planned. For now, it remains challenging to delineate the effects of core temperature and $c_{\mathrm{s}}$ gradients from each other. Combined, they adjust the cell potential so extensively that plateau identification without differential techniques introduces risk of classification error.

Reconstruction of the full-cell $Q \mathrm{~d} V \mathrm{~d} Q^{-1}$ profile from half-cell data increases confidence that the newly observed inflections are not the result of staging and demonstrates PE contributions and supports degradation mode assignment in the following section of this work. $\mathrm{d} V \mathrm{~d} x^{-1}$ data for each of the PE and NE was obtained from ${ }^{18}$ where it was recorded during charging of the electrodes. 43 sample points with a mean sampling period of $0.022\left(x\right.$ in $\left.\mathrm{Li}_{\mathrm{x}} \mathrm{C}_{6}\right)$ were obtained for the NE, while 41 sample points with a mean period of 0.024 ( $x$ in $\mathrm{Li}_{\mathrm{x}} \mathrm{Ni}_{0.4} \mathrm{Co}_{0.6} \mathrm{O}_{2}$ ) were obtained for the PE. Full-cell discharge capacity in the range $0 \mathrm{mAh}$ to $6000 \mathrm{mAh}$ was mapped to the charge (PE) and discharge (NE) capacities of the electrodes used in half-cell measurements. That is, as a function of full-cell SOC the charge capacity available in the PE, $Q_{\text {pos }}$, and charge capacity remaining in the NE, $Q_{\text {neg }}$, were obtained via Equations 5 and 6, respectively.

$$
\begin{aligned}
& Q_{\mathrm{pos}}=-\left(\frac{z_{\mathrm{cell}} S_{\mathrm{pos}}\left(C_{\mathrm{SEI}}-u\right)+1-C_{\mathrm{SEI}}-\theta_{\text {init }_{\mathrm{pos}}}}{\theta_{100_{\mathrm{pos}}}-\theta_{0_{\mathrm{pos}}}}\right) Q_{\mathrm{nom}_{\mathrm{pos}}} \\
& Q_{\mathrm{neg}}=\left(\frac{\left(\frac{z_{\text {cell }}}{c_{\mathrm{s}, \mathrm{max} \text { neg }}}\right) s_{\mathrm{neg}}\left(u-C_{\mathrm{SEI}}\right) c_{\mathrm{s}, \text { max }_{\mathrm{pos}}} \Omega}{\theta_{100_{\mathrm{neg}}}-\theta_{0_{\mathrm{neg}}}}\right) Q_{\mathrm{nom}} \\
& \Omega=\frac{v_{\text {pos }}}{v_{\text {neg }}} \frac{1-\varepsilon_{\text {pos }}}{1-\varepsilon_{\text {neg }}} \frac{1-\phi_{\mathrm{v}, \mathrm{w} \text { pos }}}{1-\phi_{\mathrm{v}, \mathrm{w}_{\text {neg }}}} \\
& z_{\mathrm{cell}}=\frac{Q_{\text {cell }}}{Q_{\text {nom }_{\text {cell }}}}
\end{aligned}
$$

where $z_{\text {cell }}$ is full-cell SOC, $C_{\mathrm{SEI}}$ the capacity lost during initial Solid Electrolyte Interphase (SEI) formation and $u$ the fraction of PE utilization. $\theta_{\text {init }_{\text {pos }}}$ is the PE stoichiometry at the start of half-cell charging in ${ }^{18}$ while $\theta_{0_{j}}$ and $\theta_{100_{j}}, j \in$ \{pos, neg\}, are the electrode stoichiometries at $0 \%$ and $100 \%$ SOC respectively. $s_{\text {pos }}$ and $s_{\text {neg }}$ are half-cell capacity adjustment factors, both initially set to unity. $Q_{\text {nom }}$ as ${ }_{\text {nom }}$ and $Q_{\text {no }}$ are 
the measured half-cell charge capacities. $c_{\mathrm{s}, \max _{\mathrm{pos}}}$ and $c_{\mathrm{s}, \text { max }_{\mathrm{neg}}}$ are the maximum possible lithium concentrations. $\varepsilon_{\text {pos }}$ and $\varepsilon_{\text {neg }}$ are the electrode porosities, $v_{\text {pos }}$ and $v_{\text {neg }}$ the electrode layer volumes, and $\phi_{\mathrm{v}, \mathrm{w}_{\mathrm{pos}}}$ and $\phi_{\mathrm{v}, \mathrm{w}_{\mathrm{neg}}}$ the volume fractions of binder, filler and otherwise inactive material in each electrode layer, for the positive and negative electrodes, respectively. $Q_{\text {cell }}$ (vector property) and $Q_{\text {nom }}$ cell are the full-cell charge withdrawn and nominal capacity, respectively. $Q_{\text {pos }}$ and $Q_{\text {neg }}$ were provided to cubic smoothing spline functions that were fitted to the half-cell $\mathrm{d} V \mathrm{~d} Q^{-1}$ data to obtain half-cell potential derivatives at the same full-cell SOC points. This enabled the normalized full-cell differential voltage to be calculated by normalizing and subtracting the $\mathrm{d} V \mathrm{~d} Q^{-1}$ profiles for each individual electrode, as per Equation 8.

$$
\left(Q \frac{\mathrm{d} V}{\mathrm{~d} Q}\right)_{\text {cell,calcd }}=Q_{\text {nom }_{\mathrm{pos}}}\left(\frac{\mathrm{d} V}{\mathrm{~d} Q}\right)_{\text {pos }}-Q_{\text {nom neg }_{\text {ne }}}\left(\frac{\mathrm{d} V}{\mathrm{~d} Q}\right)_{\text {neg }}
$$

The fit between calculated and measured full-cell $Q \mathrm{~d} V \mathrm{~d} Q^{-1}$ curves was then improved by parameter adjustment. Firstly, PE and NE potential curves underwent shrinking by different amounts. This was achieved by introducing the non-zero, positive adjustment factors, $s_{j}, j \in\{$ pos, neg\}, into Equations 5 and 6 . The physical meaning of the change is that $\mathrm{PE}$ and $\mathrm{NE}$ active mass fractions were previously overestimated. The result of the change is faster PE and NE capacity depletion for each unit of full-cell discharge, and a shrinking of both electrode potential curves along the capacity axis. This had the effect of introducing trough 1 into the calculated full-cell curve, Figure $4 \mathrm{c}$, and additionally, of producing a more negative full-cell curve, thereby improving Goodness of Fit (GoF). Secondly, electrode slippages were adjusted to minimize Residual Sum of Squares (RSS). The result of slippage adjustment was to shift both the PE and NE differential curves to a higher full-cell SOC (leftward shift on the capacity axis), albeit by different amounts. Physically, this means that prior to parameter optimisation, experimental discharge from $80 \%$ of full-cell capacity corresponded to a NE with more than the correct amount of charge, and a PE with less than the correct amount. Following the optimisation, $\mathrm{PE}$ and $\mathrm{NE}$ degrees of lithiation at the beginning of full-cell discharge were such that $\mathrm{d} V \mathrm{~d} Q^{-1}$ features occurred at the correct points. The full-cell in this study had its discharge load applied at $80 \%$ SOC which introduced a region of highly negative $\mathrm{d} V \mathrm{~d} Q^{-1}$ that is not present in the half-cell data, and thus is not present in the calculated curve at $0 \mathrm{mAh}$. Although GoF could be improved beyond the achieved $134 \mathrm{mV}$ Root-Mean-Square Error (RMSE), it is sufficient for feature assignment between the full-cell and individual electrodes. The full-cell discharge rate is sufficiently low that this is possible with the half-cell $Q \mathrm{~d} V \mathrm{~d} Q^{-1}$ curves. $^{22}$

When read from left to right, Figures $4 \mathrm{a}$ through $4 \mathrm{c}$ all correspond to full-cell discharging. Trough $1\left(\approx 512 \mathrm{mAh}, x \approx 0.56\right.$ in $\left.\mathrm{Li}_{\mathrm{x}} \mathrm{C}_{6}\right)$ is the result of a high SOC NE phase transition from intercalation stage I to II. ${ }^{23,24}$ The reduction in its intensity between reference and post-fast charge curves is likely due to the large Li concentration gradient created in graphitic particles during fast charging. The gradient results in an $\mathrm{Li}_{x} \mathrm{C}_{6}$ compound with different intercalation stages along the radial particle dimension, and the transition from stage I to II hence appearing to occur over a wider discharge window, reducing trough intensity. The rightward shifting of the trough is the result of the difference in $\frac{d c_{\mathrm{s}}}{d r}$ at End of Charge (EOC) in the reference and fast charging scenarios, discussed earlier. Higher $\frac{d c_{\mathrm{s}}}{d r}$ values delay staging because some graphite it saturated $\left(\mathrm{Li}_{1} \mathrm{C}_{6}\right)$ and requires more capacity to be withdrawn before reaching $x \approx 0.56$. For the same reason, there is a horizontal offset between black reference and colored post-fast charge curves in the insets.

Trough $2\left(\approx 1450 \mathrm{mAh}, x \approx 0.50\right.$ in $\left.\mathrm{Li}_{\mathrm{x}} \mathrm{Ni}_{0.4} \mathrm{Co}_{0.6} \mathrm{O}_{2}\right)$ is slight and is the result of a high SOC PE phase transition. Peak 3 is the result of phase equilibria in both electrodes and ends with the onset of staging in both. In the NE, this corresponds to a transition from stage II to III $\left(\approx 3200 \mathrm{mAh}, x \approx 0.31\right.$ in $\left.\mathrm{Li}_{\mathrm{x}} \mathrm{C}_{6}\right) .{ }^{25}$ Troughs $4(\approx 4155 \mathrm{mAh}, x \approx 0.21$ in $\left.\mathrm{Li}_{\mathrm{x}} \mathrm{C}_{6}\right)$ and $5\left(\approx 4720 \mathrm{mAh}, x \approx 0.16\right.$ in $\left.^{\mathrm{Li}} \mathrm{C}_{\mathrm{x}} \mathrm{C}_{6}\right)$ exist primarily from low SOC NE contributions. They correspond to graphite transitions from stage IIIa to IIIb, and from stage IIIb to stage IV, respectively.
With feature assignment complete, it is clear that electrode staging is not taking place in the range $0 \mathrm{mAh}$ to $240 \mathrm{mAh}$. Additionally, the inflections present in the inset colored curves of Figure 4a following fast charging are not present in the reference curves prior to fast charging. By induction, these new inflections indicate the end of an $\mathrm{Li}^{0}$ stripping process. Hence, even when commercial full-cell DV signatures are complicated by combined contributions from both electrodes, plating identification by DV analysis is possible. Contrary to prior claims, the technique is not restricted to use with cells containing olivine or similar PE materials with high levels of $V-x$ independence. The belief that the technique functions only at very low temperatures, such as $-20^{\circ} \mathrm{C}$ and below, is unequivocally inaccurate. Moreover, the technique has been demonstrated to provide a useful indication of lithium plating following high rate charging and in the presence of substantial self-heating, extending its application scope to future EVs featuring Level 3 fast charging or higher.

Absence of evidence is not evidence of absence.-Figures 5 a (3.6 mA.cm ${ }^{-2}$ fast charging) and $5 \mathrm{~b}\left(7.3 \mathrm{~mA} . \mathrm{cm}^{-2}\right.$ fast charging) illustrate the normalized DV profiles of the two cells subjected to medium term cycling. Two characteristics are prominent. Firstly, both cells show changes in thermodynamic behavior. Profile evolution throughout the tests is evident, with the cell charged at the higher rate showing vastly more, owing to a greater degradation rate. Secondly, as illustrated in both insets, neither $Q \mathrm{~d} V \mathrm{~d} Q^{-1}$ profile shows any newly-formed inflections to indicate the end of a lithium stripping plateau. Hence, despite the low ambient temperature, high charge current densities and evident degradation, the voltage plateau technique provides no indication of lithium plating having occurred. For those medium term test cycles sampled at the lower value of $f_{\mathrm{s}}=1 \mathrm{~Hz}$, the influence of sampling period on the ability to detect inflections was considered. Of the nine inflections recorded in this work-all with conductively cooled cells - the minimum inflection duration was $190.4 \mathrm{mAh}$, equivalent to just over 30 minutes of discharging time. Hence, the inflection period is typically long relative to the sampling period. With the reduced $f_{\mathrm{s}}$, approximately 1800 samples would be recorded during an inflection, and the reduced $f_{\mathrm{s}}$ is sufficient to detect an inflection. Moreover, since the smoothing window is defined as a percentage of dataset length, smoothing was applied at the same level, irrespective of the sampling frequency used.

However, other characteristics of the DV signatures provide a contrasting indication on plating occurrence. In Figure 5b, a nearcomplete disappearance and rightward shift of trough 1 , denoted with the upward-facing red arrow, is observable. The curve experiences a majority shift to lower cell SOC and the gradual disappearance of trough 4 . Trough 5 experiences a continuous shift to more negative values and also to lower cell SOC. In DV analysis, LLI manifests as a lateral shifting of the curves to lower values on the capacity axis. ${ }^{26}$ However, after normalizing to the reference discharge capacity, mean discharge capacity across all cycles is $99.07 \%$ with a standard deviation $\sigma$ of $0.15 \%$. Hence, the curves show very little movement at the capacity axis intersection, indicating minimal capacity fade.

If EOC for lithium-ion cells is imposed by a $V_{\max }$ criterion, the rising PE potential is typically the limiter on charge added. In this work the cell is always recharged to a capacity limit corresponding to $80 \%$ SOC and the same quantity of charge capacity is withdrawn from the $\mathrm{PE}$, and made available for discharge, irrespective of cycle number. However, the galvanostatic charge phase end point is imposed by the $V_{\max }$ criterion. Figure 6a illustrates the quantities of charge added until that end point for each of the two cells. A plot of time until $V_{\max }$ shows a similar trend. For both cells, $V_{\max }$ is reached increasingly early in the charge process with more cycles, as indicated by the negative slopes of both curves. Since the NE potential is relatively invariant at high iSOC and the PE potential gradient strongly positive, the declining $\mathrm{CC}$ phase charge quantities indicate PE slippage (stoichiometric drift) in the direction illustrated in Figure 6b. The slippage suggests the occurrence of LLI. The cell with unity State of Health $(\mathrm{SOH})$ is given in Figure 6b (i), where the vertical offset between bars represents the $\mathrm{PE}$ potential as the EOC limiter and the NE potential as the End of 

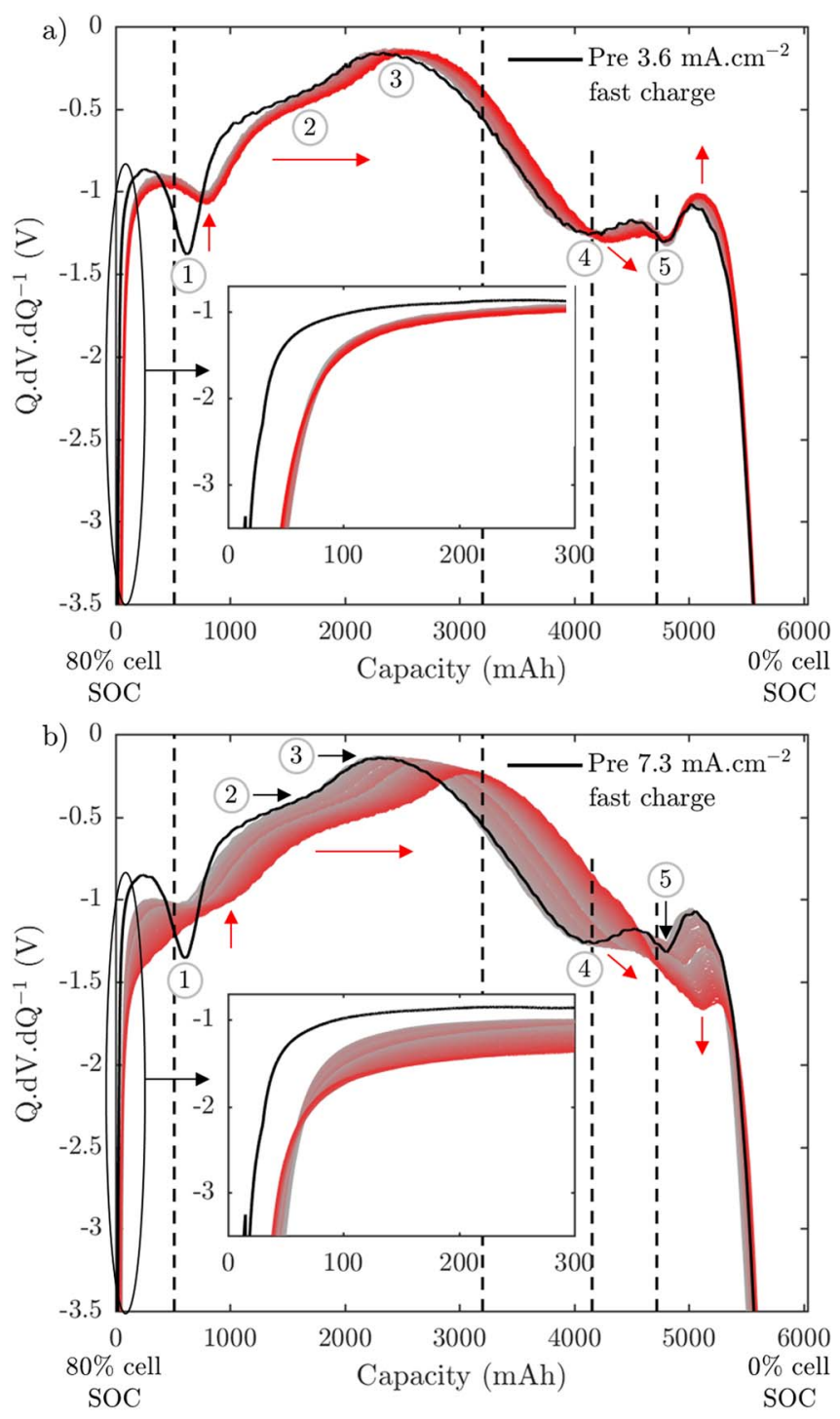

Cycle 1

Cycle 63

Figure 5. $0.1 \mathrm{~mA} . \mathrm{cm}^{-2}$ differential voltage signatures for a reference discharge (black curves) and for the following 63 discharges (colored curves) of two cells which underwent repeated fast charging. a) Cell MT1 cycled with $3.6 \mathrm{~mA} . \mathrm{cm}^{-2}$ fast charging. b) Cell MT2 cycled with $7.3 \mathrm{~mA} . \mathrm{cm}^{-2}$ fast charging. Insets show a magnified window at the beginning of discharge.

Discharge (EOD) limiter. Bar area (to scale) represents electrode capacity. Light gold colored areas are lithiated electrode material using lithium inventory nominally available for cycling. Dark gold colored areas represent the lithium inventory reserve. Dark gray (graphite) and light gray (NC) represent delithiated electrode material. During charging, the fraction of LLI that is irreversible leads to a net per-cycle loss of lithium from the PE and a transition to the state depicted in Figure $6 \mathrm{~b}$ (ii). The PE shifts downward, explaining the rightward shift of the full-cell DV curves observed in Figure 5. The lithium inventory declines, as represented by the reduction in light gold-colored area, owing to consumption via side reactions, primarily Equation 2. Moreover, at EOC although the charge corresponding to $80 \%$ SOC has been passed, the NE remains underlithiated because a fraction of the charge has been channeled via the side reactions leading to LLI. This may contribute to the reduction in trough 1 intensity as the NE struggles to reach the high degree of lithiation at which the trough occurs.
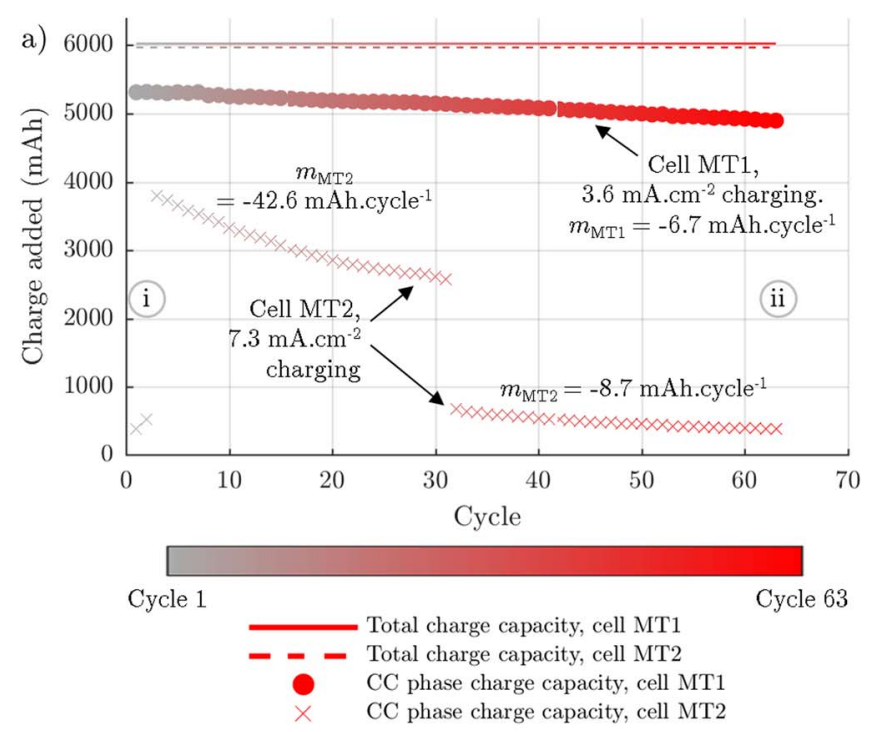

b)
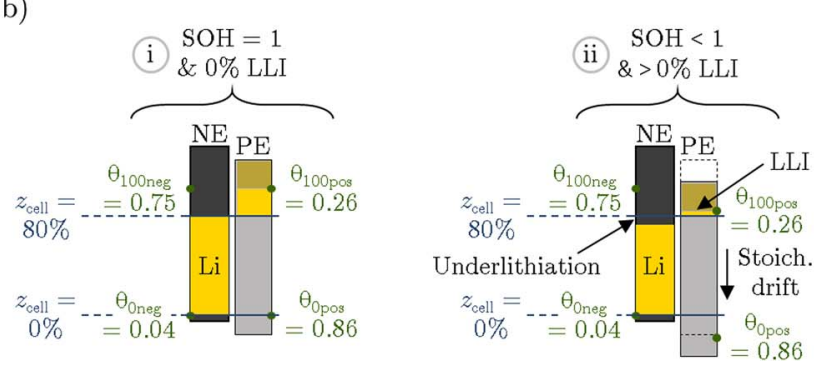

Figure 6. a) Charge added during the $\mathrm{CC}$ phase on each cycle for the two cells undergoing repeated fast charging. Negative slopes, $m_{\mathrm{MT}}$ and $m_{\mathrm{MT} 2}$, suggest PE slippage for both cells. Slopes were calculated by simple linear regression. b) Electrode utilization at full $\mathrm{SOH}$ and reduced $\mathrm{SOH}$ following LLI, underlying DV curve shifts observed in Figure 5.

The magnitude of the PE drift is unknown, but it is unlikely to be so far that at $80 \% \operatorname{SOC} \theta_{100_{\text {pos }}}$ is as low as 0.26 . If $\theta_{100_{\text {pos }}}$ was already at 0.26 following 63 cycles, or if charging had been conducted to $100 \%$ SOC from the beginning of the test, capacity loss would be evident as the lithium inventory becomes exhausted. Continued cycling beyond this point would lead to PE over-discharge and the possible collapse of the layered nickel cobalt dioxide structure. The probability of this is heightened in the particular case of the SLPB75106100 owing to the absence of Mn. ${ }^{27}$ The LLI-driven PE slippage strongly suggests the occurrence of lithium plating, in contradiction to indications from the discharge plateau technique. Although the majority of full-cell DV evolution can be explained by LLI, it is unlikely to be the only active degradation mode. With large concentration gradients within particles, Loss of Active Material (LAM) at both electrodes likely makes an additional contribution, but it is not quantified here.

For the cell MT2 curve in Figure 6a, the sudden rise (cycle 3) may be thermally-induced, while the sudden fall (cycle 32) is induced by slippage. At low cycle count, the cold cell reaches $V_{\max }$ nearly immediately with application of the high charge current. By cycle 3 , the $V_{\max }$ criterion is avoided upon initial application of the charge current. Self-heating may have driven cell core temperature above a threshold, curtailing overpotential sufficiently. Other mechanisms are possible, but were not observable. As such, substantially more charge can be added before $V_{\max }$, and the CC charge phase duration is relatively long. From cycle 32 onwards, galvanostatic phase duration has reduced so much (owing to PE slippage) that the time available for self-heating is insufficient to exceed the temperature threshold, and the process reverts to the pre-cycle 3 state. A graphical explanation 


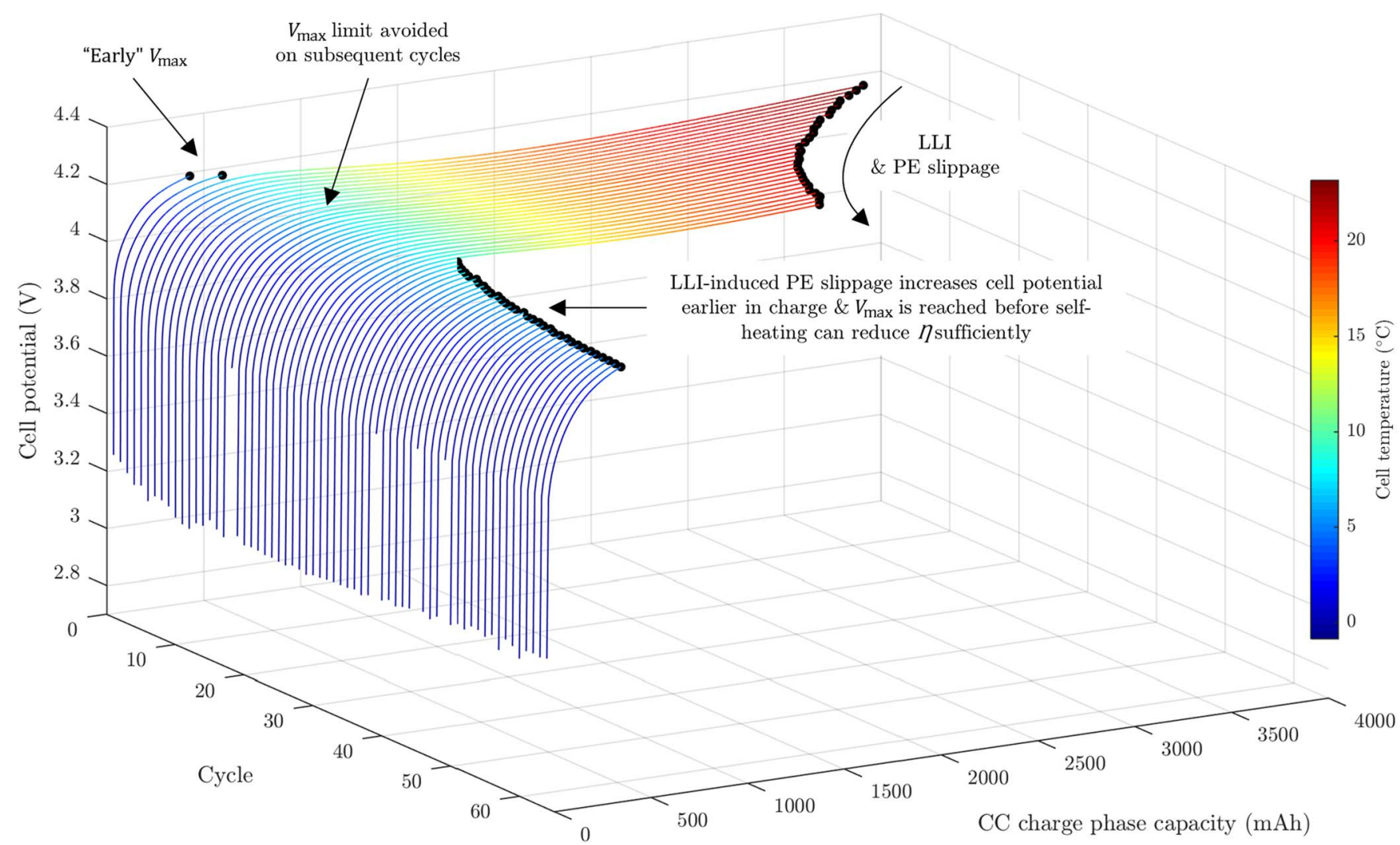

Figure 7. Circular black markers indicate cell potential reaching $V_{\max }$. Cell surface temperature, measured at a location adjacent to the tabs, is given by curve color. For cycles 3 to 31 inclusive, the temperature rise is sufficient to maintain $V<V_{\max }$ early in the charge. For all other cycles the majority of charge is instead added in the potentiostatic phase.

is provided by Figure 7 . Furthermore, that the discharge capacity of cells MT1 and MT2 is not decreasing more substantially with cycling suggests that cell kinetics are relatively unaffected. Large increases in internal resistance would reduce the discharge capacity by causing the $V_{\min }$ to be reached sooner.

Disassembly of the two cells yielded the NE images in Figures 8a and $8 \mathrm{c}$, as well as their corresponding micrographs in Figures $8 \mathrm{~b}$ and 8d. Figure 8e presents the NE of a pristine cell for comparison, with its micrograph also provided in Figure $8 \mathrm{f}$. The four circular marks present on each electrode are believed to be artifacts of the cell assembly process. All three electrode sheets are similar in their coloring. Cell MT1's NE exhibits small gray deposits around the electrode perimeter and adjacent to the copper tab-highlighted by the black braces. Cell MT2's NE exhibits a far more prominent line of deposits around the entire perimeter. This feature was evident on electrodes throughout cell MT2's stack. Additionally, in the lower middle of only this particular NE sheet's (present on both sides, one side shown only), there was an additional area of deposits producing an "L" pattern. The reason for this feature's occurrence is unknown. Preferential lithium deposition at the electrode perimeter (the "edge effect") is a widely acknowledged phenomenon, arising because of a tendency for the edge's $\mathrm{Li}$ concentration to rise faster than in the bulk of the sheet. ${ }^{28}$ The inner layers of convectively cooled cells are marginally hotter than the outer layers and therefore experience greater current densities. For that reason, they are more susceptible to lithium plating. On the other hand, their increased temperatures accelerate transport and kinetics and for that reason, they are less susceptible to lithium plating. The outermost layers of cell MT2's stack exhibited a difference in the amount of deposition between the end of the sheet with the tab (relatively more) and the opposite end (relatively less). That deposition occurs preferentially near to the tab is unsurprising. As a result however, outermost layers appeared to have lower level of total deposition than innermost layers, suggesting that in this example the effect from in- creased current density dominates vs. that from increased kinetics and transport.

Figure $8 \mathrm{~b}$ results from SEM imaging of an area of visibly unaltered NE sheet in cell MT1. i.e. an area where no deposition was observed with the naked eye. The surface morphology is similar to that of the pristine NE. Figure 8d results from imaging an area of cell MT2's NE sheet immediately adjacent to where the gray deposits were discovered on the perimeter. Its newly-developed morphology differs greatly from that in deposit-free regions of cell MT1 and in the pristine NE. A drastic reduction in inter-particle porosity is evident and results from the apparent formation of a new layer. Similar morphological changes have been observed following lithium plating elsewhere in the literature. ${ }^{29}$

For cell MT2, the EDX analysis was performed across an area at the edge of a NE sheet corresponding to a transitional region between graphite and the edge deposition. The results are presented in Figure 9 and indicate the presence of elemental carbon (blue, Atomic Percentage, at $\%,=48.2 \%$, certainty $=1.00$ ), oxygen (yellow, at $\%=$ $40.0 \%$, certainty $=1.00$ ), fluorine (purple, at $\%=11.1 \%$, certainty $=$ 0.99 ) and phosphorus (green, at $\%=0.7 \%$, certainty $=0.99$ ). The Phenom ProX did not have the ability to detect lithium. The high at $\%$ of carbon is superseded by a high at $\%$ of oxygen as the surface morphology transitions from its pristine-like state to that of the newlyformed layer. The oxygen content suggests that the layer observed in Figure 8d results from oxide formation on reactive metallic lithium during cell disassembly and exposure to air. Hence, the EDX and SEM analyzes indicate the prior occurrence of lithium plating. The fluorine and phosphorus were likely deposited following solvent evaporation and precipitation of the hexafluorophosphate.

Combined, DV signature shifting due to LLI, morphological changes observed via SEM and oxidated layer discovery by EDX on cell MT2's NE all indicate that the metallic gray deposits found on sheets in both cells are lithium plated during fast charging. The 

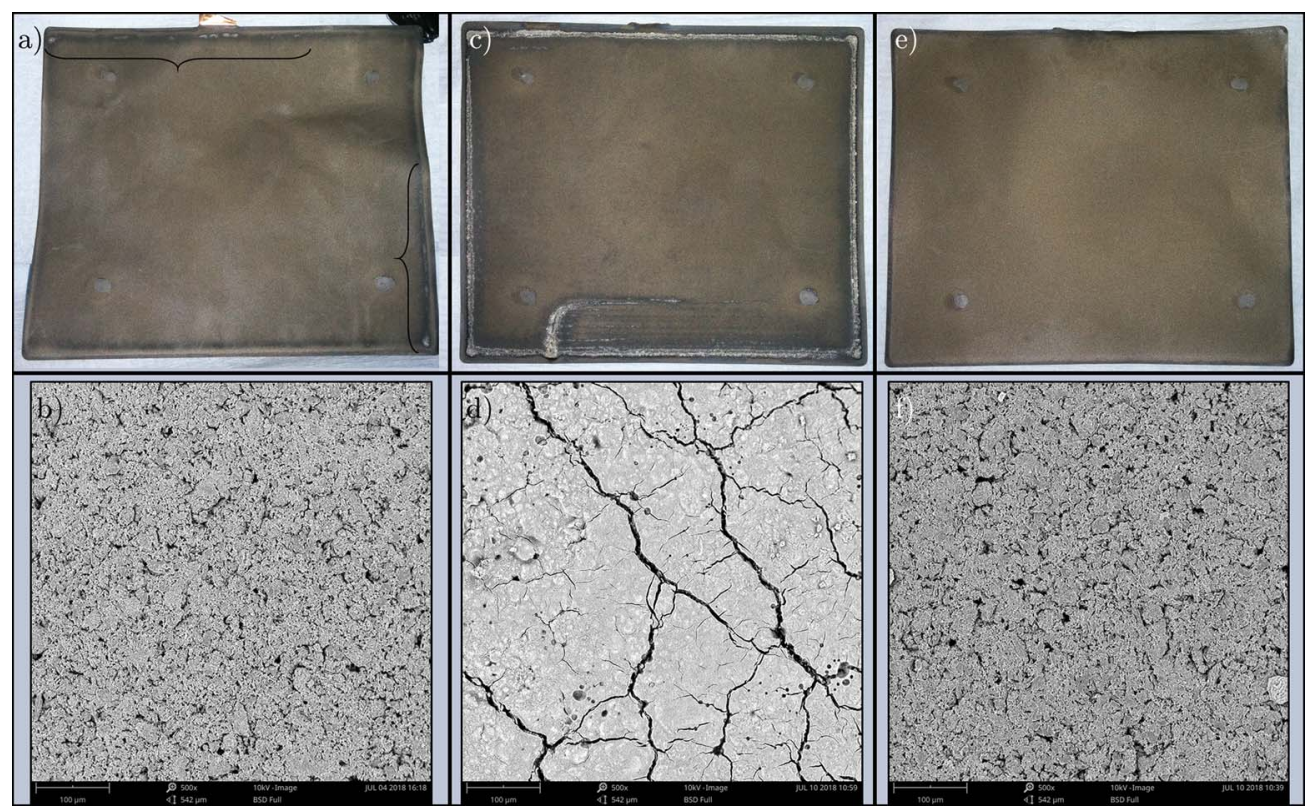

Figure 8. a) NE of the cell cycled repeatedly with $3.6 \mathrm{~mA} \cdot \mathrm{cm}^{-2}$ charging showing a small amount of visible lithium plating near its perimeter, particularly at the tab. b) SEM micrograph of a location approximately in the center of the electrode in 'a)' illustrating a similar morphology to that of the pristine electrode. c) NE of the cell cycled repeatedly with $7.3 \mathrm{~mA} . \mathrm{cm}^{-2}$ charging showing extensive lithium plating near its perimeter and at the end opposite the tab. d) SEM micrograph at a location near the perimeter of the electrode in 'c)' illustrating a substantially evolved morphology. e) NE of a pristine cell for reference. f) SEM micrograph of the pristine NE given in 'e)' illustrating morphology at the beginning of life.

results demonstrate that while the occurrence of lithium plating can be identified with the voltage plateau technique using DV analysis, the absence of plating cannot be reliably identified by the same method. This is the case even if that cell SOC level at EOC is known to result in plating with a non-zero reversible component. ${ }^{9}$ Moreover, it is the case even when the quantity of deposited lithium is visually extensive, suggesting at the very least, that any minimum areal coverage threshold can be higher than previously believed. ${ }^{11,14}$ Hence, interpretation of the absence of a new $Q \mathrm{~d} V \mathrm{~d} Q^{-1}$ inflection (equivalent to the absence of a plateau) as an absence of lithium plating creates the possibility of a false negative result. One cannot correctly claim that no plateau correlates with no plating. This is especially dangerous because, as shown, the plating can be extensive. Programmatic appli-

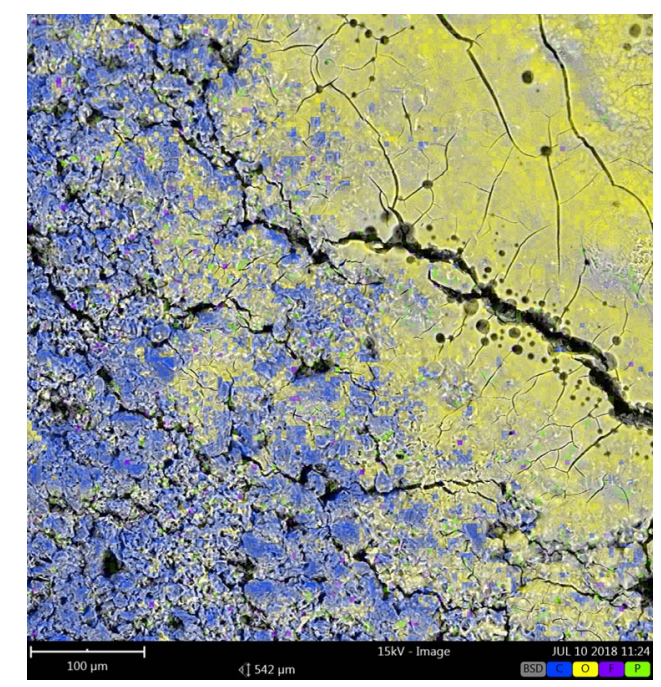

Figure 9. SEM micrograph and elemental mapping of a NE area following 63 cycles of charging at $7.3 \mathrm{~mA} . \mathrm{cm}^{-2}$. Surface morphology of the high-carbon region (blue) noticably evolves moving rightwards to an area of localized lithium plating and high at $\%$ of oxygen (yellow). cation must therefore occur with the new knowledge that an absence of a plateau does not ensure continued operation will avoid cell failure from dendrite growth. BMS implementation of the technique without this consideration presents a large safety concern.

Investigation of the cause of this behavior will be the subject of future work. However, five possible explanations are introduced here. Theories $\mathrm{i}$ and $\mathrm{ii}$ are predicated on the basis that $\mathrm{Li}^{0}$ deposition occurred with a reversible component, but that the subsequent stripping was undetectable. i.e. stripping did occur. Theories iii to $\mathrm{v}$ are predicated on the alternative basis that, at the beginning of discharge, there was no reversibly-plated $\mathrm{Li}^{0}$ available and hence a dearth of reactant for the stripping process. i.e. stripping did not occur. i) Minimum coverage threshold: The areal coverage of $\mathrm{Li}^{0}$ on NE particles is below a minimum threshold required for detection. This is unlikely, because following only a single fast charge of the conductively cooled cell $\mathrm{E}$ $\left(1.8 \mathrm{~mA} . \mathrm{cm}^{-2}\right.$, where the quantity of deposited $\mathrm{Li}^{0}$ was likely much less than in cells MT1 or MT2), $Q \mathrm{~d} V \mathrm{~d} Q^{-1}$ inflections emerged. ii) Increased $\mathrm{Li}^{0}$ oxidation potential: Variations in cell temperature have recently been shown to influence plateau length during relaxation. ${ }^{11}$ Similarly, increased temperature can increase or decrease the oxidation potential of $\mathrm{Li}^{0}$ during cell discharge according to the Nernst equation, where the direction is defined by the sign of the reaction quotient. In doing so, the mixed potential could be adjusted upward to more a positive potential with respect to $\mathrm{Li} / \mathrm{Li}^{+}$, closer to the singular potential of oxidation by Equation 1. Hence, the stripping plateau's departure from the normal terminal voltage profile is less. It is conceivable that it is so much less that no plateau is detected. iii) Reaction reversibility: If the deposition reaction (Equation 2) was in this case wholly irreversible, then no plateau would appear because no reactant would be available. This is an unlikely cause because the relatively large quantities of stripped lithium suggest a high degree of process reversibility across a wide range of fast charging rates. iv) Fast chemical intercalation: High cell temperature resulting from self-heating may accelerate CI beyond a threshold. In doing so, deposited Li that could otherwise be recovered via stripping instead chemically intercalates during the potentiostatic charge phase, leaving only irreversibly-deposited Li and no stripping plateau. v) Accelerated side reactions: High cell temperature could accelerate side reactions between the $\mathrm{Li}^{0}$ and electrolyte, forming SEI constituents and reducing or eliminating the 


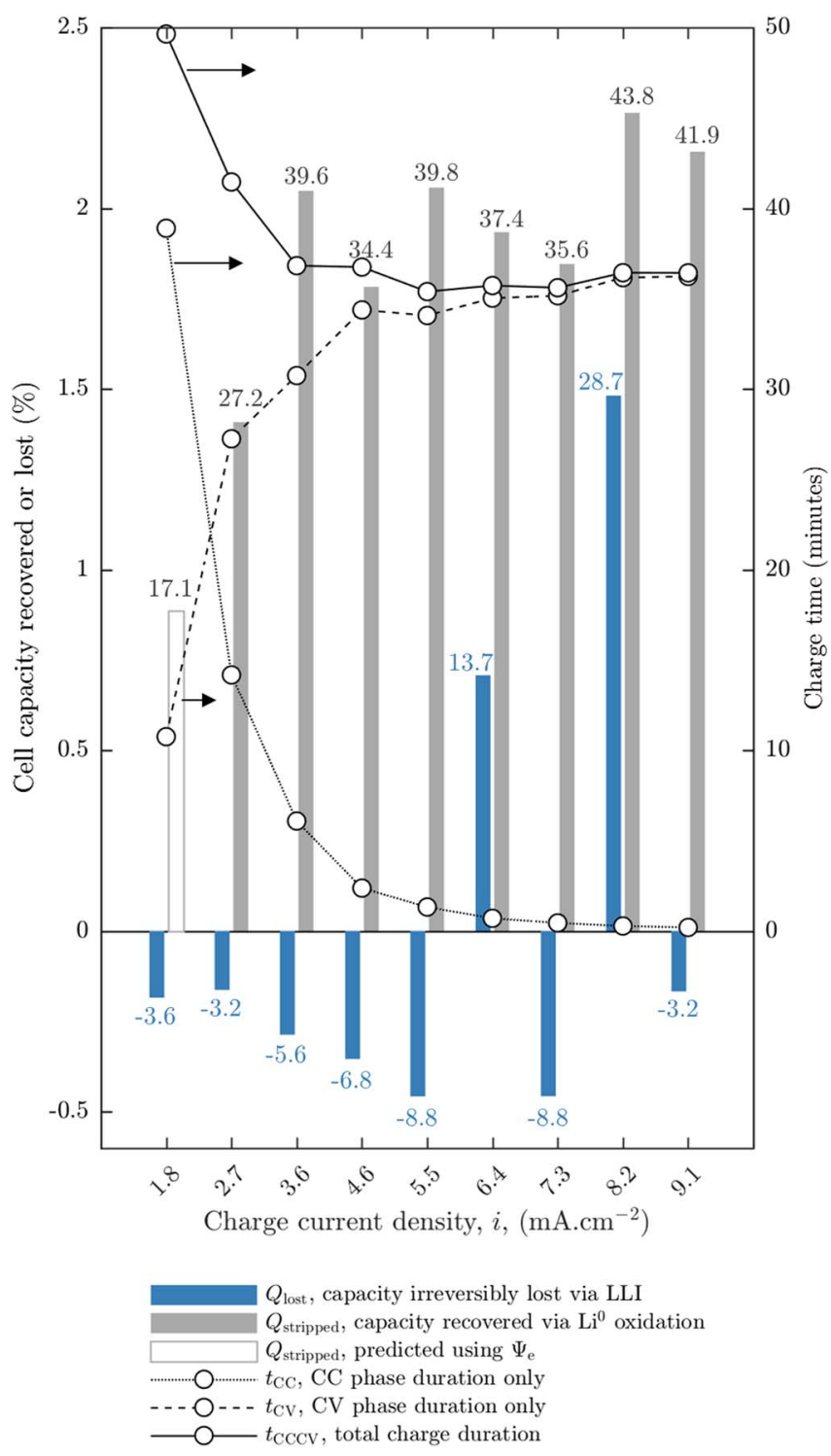

Figure 10. Bars illustrate cell capacity changes following a single fast charge cycle as a percentage of measured cell capacities. Quantities above/below bars depict the corresponding masses of lithium in $\mathrm{mg}$, i.e. $\mathrm{Li}_{\text {stripped }}$ and $\mathrm{Li}_{\text {lost }}$. Curves illustrate durations of the $\mathrm{CC}$ or $\mathrm{CV}$ charge phases, or the combined duration of both phases, during the fast charge at each rate.

strippable $\mathrm{Li}^{0}$. This would leave no reactant available for the stripping reaction.

Plating quantification accuracy: theoretical analysis.-Figure 10 illustrates the mass of discharge-phase oxidated $\mathrm{Li}^{0}\left(\mathrm{Li}_{\text {stripped }} \in\right.$ $\left.\mathbb{R}^{+}\right)$and the lithium mass irreversibly lost $\left(\mathrm{Li}_{\text {lost }} \in \mathbb{R}\right)$ for each conductively cooled cell subjected to a single fast charge. In theory, $\mathrm{Li}_{\text {lost }} \leq 0$ should hold true, where negative values represent irreversible loss. In practice, $\mathrm{Li}_{\text {lost }}>0$ is reported in two cases; following $6.4 \mathrm{~mA} . \mathrm{cm}^{-2}$ and $8.2 \mathrm{~mA} . \mathrm{cm}^{-2}$ charging. That is to say, the total number of conductively cooled cells demonstrating capacity gain was two, out of a total of nine cells tested. The reason for these outlying results, representing an apparent capacity increase following fast charging, is unknown, but Coulombic Efficiency (CE) values above unity have been encountered before. ${ }^{30}$ Cell temperature at EOD has returned to approximately the ambient and is therefore unlikely to be influential. The effect may stem from the recovery of lithium stored in the NE overhanging regions or from an accumulation of cycler error in the coulomb counted charge and discharge capacities. In all scenarios, lithium mass was calculated according to Equation 9 where all discharge capacity to the end of a high-voltage plateau, specifically given by the minimum in the $Q \mathrm{~d} V \mathrm{~d} Q^{-1}$ inflection, is assumed to be solely sourced from $\mathrm{Li}^{0}$ stripping. ${ }^{1,9,31}$ This is representative of the current state of knowledge, but is not without challenge, ${ }^{11}$ and its validity will be investigated in a future work.

$$
\mathrm{Li}_{j}=\frac{Q_{j} M_{\mathrm{Li}}}{F}
$$

where $\mathrm{Li}_{j}, j \in$ \{stripped, lost $\}$ is the mass of $\mathrm{Li}^{0}$ stripped or lost. $Q_{j}$ is, for stripped lithium, the discharge capacity until the end of the stripping plateau ( $j=$ stripped) and, for irreversibly lost lithium, is the difference between pre and post fast charge capacity upon reaching $V_{\min }(j=$ lost $) . M_{\mathrm{Li}}\left(6.94 \mathrm{~g} \cdot \mathrm{mol}^{-1}\right)$ is the molar mass of lithium and $F$ the Faraday constant. Percentage capacity change was calculated using each cell's measured capacity.

The goal is to obtain an accurate a posteriori estimate of the amount of lithium plated across a charge-discharge cycles invovling fast charging, $\mathrm{Li}_{\text {plated }} \in \mathbb{R}^{+}$. Doing so enables programmatic, online $\mathrm{SOH}$ evaluation and additionally supports fast charging algorithm development. The challenge lies in using measurements of stripping and irreversible loss to achieve that goal. If one quantifies only the reversibly stripped Li mass and neglects the irreversible component, as in Ref. 11, one naturally underestimates the plated quantity. If one sums both, as in Ref. 9, one employs Equation 10.

$$
\left|\mathrm{Li}_{\text {plated }}\right|=\left|\sum_{\gamma=1}^{a}\left(\operatorname{Li}_{\text {stripped }_{\gamma}}\left(i_{\text {dschg }}\right)-\operatorname{Li}_{\text {lost }_{\gamma}}\right)\right|
$$

where an update is made here so that $\mathrm{Li}_{\text {stripped }}$ is a function of the discharge current density, $i_{\mathrm{dschg}}$. This dependency was suggested in the work of Yang et al. (2018), ${ }^{11}$ but on the observation of shifting $\mathrm{d} V \mathrm{~d} Q^{-1}$ inflections that were likely the result of graphite staging rather than plateau end points. In Figure $6 \mathrm{~b}$ of their work, both inflections, at $0.4 \mathrm{Ah}(\mathrm{C} / 3$ discharge $)$ and at $0.95 \mathrm{Ah}(1 \mathrm{C}$ discharge $)$, exhibit trough intensities more similar to those produced by graphite staging from stages I to II than to those shallow, narrow troughs at plateau end points. Moreover, if graphite NE stoichiometry limits are assumed as $\theta_{0_{\text {neg }}}=0.04, \theta_{100_{\text {neg }}}=0.75$, then these $\mathrm{d} V \mathrm{~d} Q^{-1}$ inflections occur at $x=0.58(\mathrm{C} / 3$ discharge $)$ and at $x=0.54$ (1C discharge). This assumption is reasonable since graphite is normally not fully lithiated in commercial cells, and is capable of complete or near-complete delithiation without instability. I to II staging has been demonstrated to occur in that vicinity; $x=0.50$ (literature $^{23-25}$ ) and $x \approx 0.56$ (earlier in this work). Also, in our work, all stripping plateau end points occurred prior to NE I to II staging in the range $x \geq 0.59$. This observation highlights the benefits of a rigorous full cell DV feature assignment.

Nonetheless, this work's Figure 11 demonstrates that there is a dependency of $\mathrm{Li}_{\text {stripped }}$ on $i_{\mathrm{dschg}}$. The results indicate that higher discharge rates obfuscate the plateau end point inflection and prevent its detection. That is, $\mathrm{Li}_{\text {stripped }}$ was not quantifiable at the two higher discharge rates used. This presents a challenge for practical online implementation of the technique where the conventional $\mathrm{C} / 20$ rate requires a significant period of time to reach the plateau end -25.7 minutes or $2.7 \%$ of the total discharge duration. The remaining $97.3 \%$ (15 hours \& 36 minutes) of discharge must then elapse to obtain the value of $\mathrm{Li}_{\text {lost }}$. Without an improved understanding of how $\mathrm{Li}_{\text {stripped }}$ depends upon $i_{\mathrm{dschg}}$, accelerating quantification by increasing discharge rates remains unreliable. It additionally highlights a new difficulty with reliable plating identification, since a false negative test result is possible if higher discharge rates are employed.

To further advance the estimation accuracy of Equation 10, consider the $\mathrm{CI}$ of deposited $\mathrm{Li}^{0}$, otherwise known as $\mathrm{Li}^{0}$ dissolution. CI is a diffusion process by which plated $\mathrm{Li}^{0}$ intercalates into unsaturated $\mathrm{C}_{6}$ according to the irreversible reaction of Equation 11. If plating was driven by Solid Diffusion Limitation (SDL), the host $\mathrm{C}_{6}$ may be an adjacent NE particle to the one which has become saturated. $\mathrm{Li}^{0}$ undergoing $\mathrm{CI}$ is wholly neglected by both terms in Equation 10 if the $\mathrm{CI}$ process completes prior to discharge beginning. Partial completion 


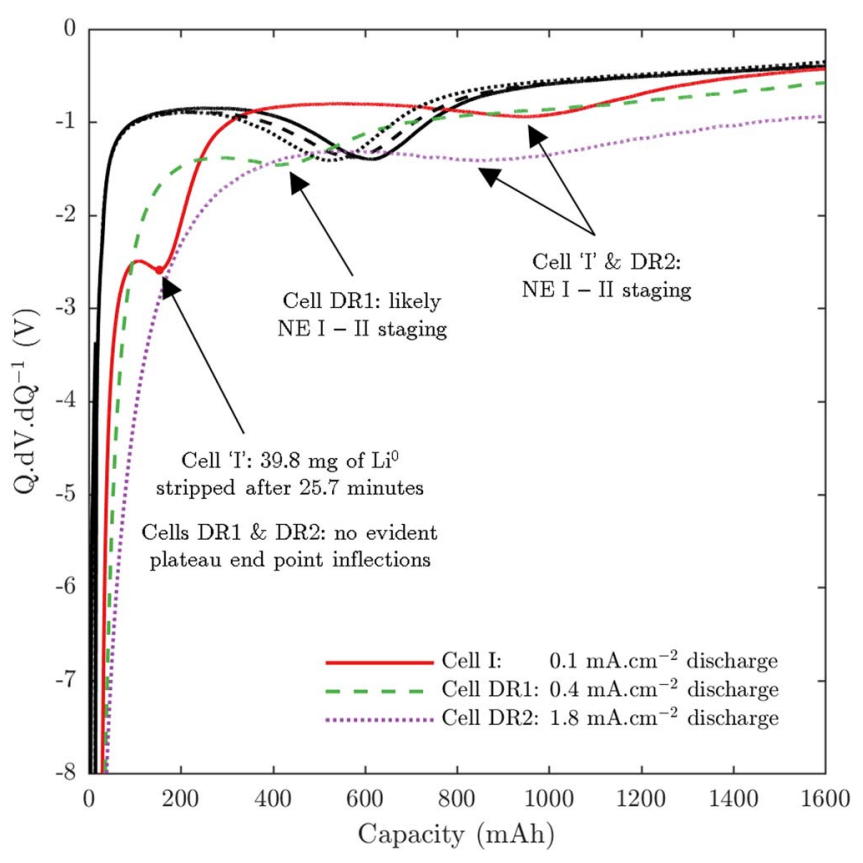

Figure 11. Differential voltage signatures of the three cells (cell IDs I, DR1 \& DR2) charged at $5.5 \mathrm{~mA} . \mathrm{cm}^{-2}$ and discharged at the different rates given in the figure legend. Black curves represent discharges of the same cells following $0.2 \mathrm{~mA} . \mathrm{cm}^{-2}$ charge, prior to any fast charge/plating, for reference.

is possible, and hence the rate of $\mathrm{CI}$ is important.

$$
y \mathrm{Li}^{0}+\mathrm{Li}_{x} \mathrm{C}_{6} \rightarrow \mathrm{Li}_{x+y} \mathrm{C}_{6}, \quad \text { for } 0 \leq x+y \leq 1
$$

From the reduction in rate of LLI with cycling (exemplified by $-42.6 \mathrm{mAh} . \mathrm{cycle}^{-1}$ to $-8.7 \mathrm{mAh}$.cycle ${ }^{-1}$ ) upon shortening of the CC phase in convectively cooled cells in Figure 6 , it can be inferred that a majority of lithium plating occurs during the $\mathrm{CC}$ rather than $\mathrm{CV}$ phase. With conduction cooling for all cells in Figure 10, this CC phase deposition is likely to be amplified. As a result, CV phases begin with a NE areal coverage of $\mathrm{Li}^{0}$. Short $\mathrm{CV}$ phase durations are considered incapable of facilitating substantial CI. ${ }^{9}$ However, under fast charging conditions with relatively long $\mathrm{CV}$ phases and decaying plating current density, $i_{\mathrm{pl}}$, according to Equation 12 , the $\mathrm{CV}$ phase provides an opportunity for substantial CI of deposited $\mathrm{Li}^{0}$. In-situ neutron diffraction experiments on graphite-NMC cells support the coincidence of the $\mathrm{CV}$ phase start and CI of plated $\mathrm{Li}^{0}{ }^{32}$

$$
\begin{gathered}
\lim _{t_{\mathrm{CV}} \rightarrow t_{\alpha}} i_{\mathrm{pl}}=0 \\
i_{\mathrm{pl}}=i_{\mathrm{chg}}-i_{\text {int }}\left(i_{\mathrm{chg}}\right)-i_{\mathrm{sr}}^{0}
\end{gathered}
$$

where $t_{\mathrm{CV}}$ here is elapsed time in the $\mathrm{CV}$ phase and $t_{\alpha}$ the time at which lithium plating ceases because the charge process is no longer governed by a Charge Transfer Limitation (CTL) or SDL. $i_{\text {chg }}$ is charge current density applied by the battery cycler, $i_{\text {int }}$ the charge current density constituting Li intercalation and $i_{\mathrm{sr}}$, assumed zero here, is the charge current density involved in side reactions other than lithium plating. The ratio $\frac{i_{\text {int }}}{i_{\mathrm{pl}}}$ is a function of $i_{\text {chg }}$. Since CI detracts from the measurable quantities on the subsequent discharge, Equation 13 provides an improved estimate.

$$
\left|\mathrm{Li}_{\text {plated }}\right|=\left|\sum_{\gamma=1}^{a}\left(\operatorname{Li}_{\text {stripped }_{\gamma}}\left(i_{\text {dschg }}\right)-\operatorname{Li}_{\text {lost }_{\gamma}}+\operatorname{Li}_{\text {chemical }_{\gamma}}\left(t_{\mathrm{CV}}, T\right)\right)\right|
$$

$$
\mathrm{Li}_{\text {chemical }}=A_{\text {cell }} M_{\mathrm{Li}} \int_{0}^{t_{\mathrm{CV}}} N_{\mathrm{Li}}(t, T) d t
$$

where $\mathrm{Li}_{\text {chemical }} \in \mathbb{R}^{+}$is the mass of plated lithium that chemically intercalated across $a$ number of cycles, $A_{\text {cell }}$ is the cell's electrochemically active surface area and $N_{\mathrm{Li}}$ the molar flux associated with chemical intercalation of the plated lithium. $\mathrm{Li}_{\text {chemical }}$ magnitude cannot be measured during discharge since Li that was plated, chemically intercalated and subsequently deintercalated appears no differently from all other charge sourced by deintercalation. However, the theory presented by Petzl \& Danzer that plating irreversibility is a maximum at high SOC in part because of increased CI suggests $\mathrm{Li}_{\text {chemical }}$ is substantial in magnitude. ${ }^{9} \mathrm{Li}_{\text {chemical }}$ can be quantified by i) modeling the rate of $\mathrm{CI}$ as a function of the parameters upon which it depends or ii) by using other non-destructive techniques to quantify the plating extent until the $\mathrm{CC}$ charging phase end point, and subtracting the discharge-phase quantity obtained by application of Equation 10. Very recently, there have been indications that in-situ charge-phase plating detection ${ }^{33}$ and quantification $^{31}$ are possible.

The complexity of the process is high because charge rate influences parameters upon which $\mathrm{Li}_{\text {chemical }}$ depends, $\left(t_{\mathrm{CV}}, T\right)$. Results exist $^{32}$ indicating that the rate of $\mathrm{CI}$ is independent of the areal coverage of $\mathrm{Li}^{0}$ but the literature on this is not in complete agreement. ${ }^{16}$ Further, it has been suggested that the CI rate depends on additional parameters ${ }^{15}$ - plating morphology, NE material, distribution of NE particle size, NE porosity, electrolyte composition, internal cell pressure and the solid phase concentration gradient $\frac{d c_{\mathrm{s}}}{d r}$ where $r$ is the spatial dimension along NE particle radii. With the exception of $\left(t_{\mathrm{CV}}, T, \frac{d c_{\mathrm{s}}}{d r}\right)$, many or all of these parameters are or can be reasonably assumed to be, identical across all cells tested in this work. Time for $\mathrm{CI}$ to occur is illustrated by the curves in Figure $10 . t_{\mathrm{CC}}$ falls exponentially as $V_{\max }$ is reached earlier with higher $i$. $t_{\mathrm{CV}}$ initially increases exponentially with increasing charge current density and thereafter plateaus when the phase constitutes the vast majority of total charge time $\left(\frac{t_{\mathrm{CV}}}{t_{\mathrm{CCCV}}} \geq 0.94,4.6 \mathrm{~mA} . \mathrm{cm}^{-2} \leq i \leq 9.1 \mathrm{~mA} . \mathrm{cm}^{-2}\right)$. Total charge time therefore becomes insensitive to additional charge rate increases. $\mathrm{Li}_{\text {chemical }}$ increases as charge current density does because $t_{\mathrm{CV}}$ increases. Similarly, higher values of current density lead to increased heat generation and higher temperatures that accelerate $\mathrm{CI}$. Since $t_{\mathrm{CV}}$ and $T$ are positively correlated with both the charge rate and the quantity $\mathrm{Li}_{\text {chemical }}$, the faster the charging, the greater the amount by which Equation 10 underestimates $\mathrm{Li}_{\text {plated }}$. This is especially problematic because, under some circumstances, accurate plating quantification is more useful following higher rate charging when plating is most likely, than under lower rate charging.

It is dangerous to ignore the chemically intercalated amount because underestimation of plating could lead to continued cell operation in spite of dendrite formation and the possibility of a short circuit. Hence, this work advocates for an update of existing plating quantification methods by accounting for $\mathrm{Li}_{\text {chemical }}$ whenever a potentiostatic charge phase is employed. A future work will attempt to quantify $\mathrm{Li}_{\text {chemical }}$. We hypothesize that as $\mathrm{Li}_{\text {plated }}$ exceeds its true maximum, the calculated (reported) value will decrease because $\mathrm{Li}_{\text {chemical }}$ increases (long CV phase durations). Moreover, as charge rates are increased beyond that at which $\mathrm{Li}_{\text {plated }}$ is a maximum, the true amount of $\mathrm{Li}_{\text {plated }}$ declines because the shortening $\mathrm{CC}$ phase duration allows less time for plating. The trend of initial growth and later decline in $\left|Q_{\text {lost }}\right|$ in Figure 10 supports this theory.

Gradient-based sensitivity compensation.-Diagnostics algorithms are required to be robust for plating quantification both by researchers and by programmatic methods on a BMS. Furthermore, fast charging algorithm development would benefit from increased sensitivity to enable quantification of smaller amounts of lithium plated. The DV inflection characterizing a stripping plateau end point typically involves one peak and one trough in close succession. The peak occurs immediately prior to the end of $\mathrm{Li}^{0}$ stripping when the cell potential is falling at its lowest rate since the beginning of discharge. When the source of $\mathrm{Li}^{0}$ becomes depleted, the NE potential transitions from mixed to the singular potential of de-plated $\mathrm{Li}_{\mathrm{x}} \mathrm{C}_{6}$ and the rate of cell potential decline increases, returning the cell potential to 
that of a cell with no plated lithium. This is observed as the voltage plateau ending, and the $Q \mathrm{~d} V \mathrm{~d} Q^{-1}$ trough occurs when this decline is steepest. Both the peak and trough are hence real positive roots of $Q \mathrm{~d}^{2} V \mathrm{~d} Q^{-2}$. Determination of $Q_{\text {stripped }}$ is a root finding problem in which the discharge capacity at the second root is being sought.

$Q \mathrm{~d} V \mathrm{~d} Q^{-1}$ inflections can be considered to start and end as they diverge and converge from/to the DV gradients of healthy cells undergoing discharge (e.g. reference discharges). As such, inflections here are considered to have started upon Equation 14 being satisfied and are considered to have ended when Equation 15 is satisfied. A criterion on the first derivative is required for inflection end point determination because the second derivative criterion can be satisfied twice; firstly, just prior to the inflection's trough and secondly, at the true inflection end point. The criteria were determined by visual inspection of the DV curves vs. their reference curves and then applied universally to evaluate start and end points in all tests. The criteria are specific to the cell chemistry and cell design, and are therefore empirical parameters needing re-evaluation for other cells whose DV behavior may differ.

$$
\text { start: } Q \frac{\mathrm{d}^{2} V}{\mathrm{~d} Q^{2}}<0.281 \mathrm{VmAh}^{-1}
$$

$$
\text { end: } Q \frac{\mathrm{d}^{2} V}{\mathrm{~d} Q^{2}}<0.003 \mathrm{VmAh}^{-1} \wedge Q \frac{\mathrm{d} V}{\mathrm{~d} Q}>-2 \mathrm{~V}
$$

The problem of root finding is therefore simplified by knowledge of the start and end points of the interval in which the inflection lies, the "inflection range". These are given in terms of $Q$ discharged, where the start point is denoted $\Psi_{\mathrm{s}}$ and the end point $\Psi_{\mathrm{e}}$. These start and end points are unique to each dataset. $10^{\text {th }}$ degree polynomials were fitted to the $Q \mathrm{~d} V \mathrm{~d} Q^{-1}$ curves in the inflection range because numerical differentiation of the data produces excessive noise, in spite of the raw $V$ data having been smoothed. Resulting GoF was high at $\leq 35 \mathrm{mV}$ RMSE (mean $=24 \mathrm{mV}$ ) in all cases. Differentiation of those polynomials yielded nine $9^{\text {th }}$ degree polynomials describing $Q \mathrm{~d}^{2} V \mathrm{~d} Q^{-2}$. For each dataset, the number of real roots lying in the inflection range was determined by obtaining the eigenvalues of the companion matrices. Two positive real roots were found in the range $\Psi_{\mathrm{s}}$ to $\Psi_{\mathrm{e}}$ for each fast charging scenario, except $1.8 \mathrm{~mA} . \mathrm{cm}^{-2}$ fast charging where no real roots were discovered. The values of the real positive roots need not be known at this stage. Knowledge of the number of such roots occurring in the range $\Psi_{\mathrm{s}}$ to $\Psi_{\mathrm{e}}$ is sufficient to determine if the conventional stripping quantification method can be applied. As such, a method such as Sturm's theorem may be used here if numerical root finding is unfeasible.

Plotting the first derivatives provides additional insight. Figure $12 \mathrm{a}$ illustrates a DV profile (purple) representing a stripping process occurring following $1.8 \mathrm{~mA} . \mathrm{cm}^{-2}$ charging. However, no typical peaktrough formation and corresponding roots are present since, for this low level of $\mathrm{Li}^{0}$ stripping, the high voltage plateau was never so high as to be able to fall substantially at its end point. Physically, this suggests a lesser contribution from the $\mathrm{Li}^{0}$ to the mixed NE potential, and a relatively greater contribution from $\mathrm{Li}_{\mathrm{x}} \mathrm{C}_{6}$. In such a case, stripping quantification is necessary for plating quantification, but the conventional method is not robust, produces an indeterminate result and demonstrates the limited sensitivity of the technique. Although DV profiles are available for all rates given in the lower subplot (i.e. legend of Figure $12 \mathrm{~b}$ ), only a representative sample are shown in Figure 12a. This is so because from $3.6 \mathrm{~mA} . \mathrm{cm}^{-2}$ to $9.1 \mathrm{~mA} . \mathrm{cm}^{-2}$ all DV curves are extremely similar and their minima cluster in approximately the same location on the graph, making it difficult to read.

To compensate for this limitation and obtain an estimate of $Q_{\text {stripped }}$, it is noted that a positive linear relationship exists between $Q_{\text {stripped }}$ as measured to inflection minima and the discharge capacity to the end of the inflections, $\Psi_{\mathrm{e}}$. Figure $12 \mathrm{~b}$ visually exemplifies this relationship, which is substantiated by a Pearson Correlation Coefficient (PCC), $\rho_{\mathrm{Q}_{\text {stripped }}, \Psi_{\mathrm{e}}}$, of $0.98,-1 \leq \rho^{\mathrm{PCC}} \leq 1 . \rho^{\mathrm{PCC}}$ values approaching -1 indicate a strong, negative linear correlation, while $\rho^{\mathrm{PCC}}$ values approaching 1 indicate a strong, positive linear correlation, and a $\rho^{\mathrm{PCC}}$
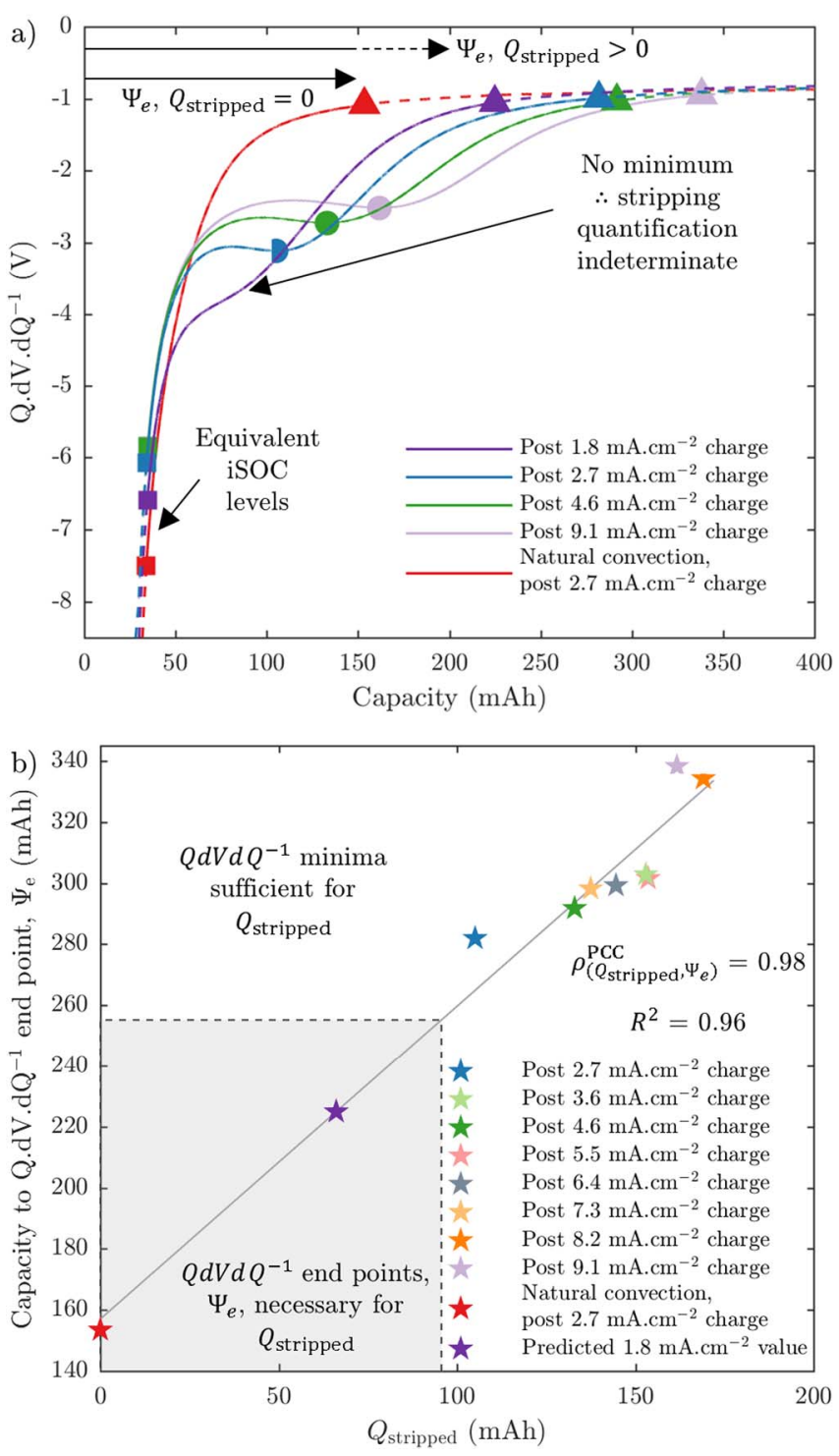

Figure 12. a) Normalised $1^{\text {st }}$ derivatives of beginning-of-discharge cell potential for conductively-cooled cells E, F, H and M, as well as convectively-cooled cell A (red curve), following fast charging at the rates given in the legend. Circular markers represent the minima used to calculate $Q$ recovered via stripping (gray bar magnitudes in Figure 10). Square markers represent inflection start points and triangular markers inflection end points. Data between start and end points is illustrated with a solid line while data outside of the endpoints is illustrated with a dashed line. b) Capacity to inflection end, $\Psi_{\mathrm{e}}$, can be used to predict (mean) $Q_{\text {stripped }}$ to inflection minima assuming a normal distribution of $Q_{\text {stripped }}$ about a mean of $\frac{\Psi_{\mathrm{e}}-157.01}{1.03}$. The variables exhibit a good linear correlation. The trend line, fitted to all non-purple markers, has been used to predict the value of $Q_{\text {stripped }}$ for $1.8 \mathrm{~mA} . \mathrm{cm}^{-2}$ charging, which is represented with the purple marker.

value of 0 indicates no linear correlation.

$$
\rho_{\mathrm{Q}_{\text {stripped }}, \Psi_{\mathrm{e}}}^{\mathrm{PCC}}=\frac{\operatorname{cov}\left(Q_{\text {stripped }}, \Psi_{\mathrm{e}}\right)}{\sigma_{Q_{\text {stripped }}} \sigma_{\Psi_{\mathrm{e}}}}
$$

where cov is the covariance of $Q_{\text {stripped }}$ and $\Psi_{\mathrm{e}}$. Simple linear regression is therefore justified and has been performed on the data. Since stripping inflection troughs are less severe, evidenced by the lack of a minimum, for lower quantities of $Q_{\text {stripped }}$, the DV recovery period (until the curve asymptotes) is less. Hence, $Q_{\text {stripped }}$ may be considered the independent (i.e. explanatory) variable and $\Psi_{\mathrm{e}}$ the dependent (i.e. response) variable. The regression model is therefore $\Psi_{\mathrm{e}}=m Q_{\text {stripped }}+c$ where $m$ and $c$ represent regression line slope and offset, respectively. 
The model implication is that the transition from mixed to singular NE potential is longer because of increased quantities of stripped $\mathrm{Li}^{0}$. That is, the stripping inflection end points contain information on the extent of stripping, and may be used to estimate $Q_{\text {stripped }}$ when the conventional technique fails. Because prediction of the (mean) independent variable $Q_{\text {stripped }}$ using $\Psi_{\mathrm{e}}$ is desired, $Q_{\text {stripped }}$ is regressed on $\Psi_{\mathrm{e}}$. That is, the regression minimizes the sum of the squares of residuals in a way that minimizes the error in predicted mean $Q_{\text {stripped }}$ (horizontal distances between markers and the trend line in Figure 12b).

Using only the data obtained in conductively cooled tests this regression is possible only in the range $2.7 \mathrm{~mA} . \mathrm{cm}^{-2}$ to $9.1 \mathrm{~mA} . \mathrm{cm}^{-2}$, since no $Q_{\text {stripped }}$ data point exists for the $1.8 \mathrm{~mA} . \mathrm{cm}^{-2}$ case. Although conductively cooled reference discharge data (black curves, inset in Figure 4) provides voltage gradient information for the case of $Q_{\text {stripped }}=0$, they were obtained with iSOC $\approx$ SOC, and hence exhibit a $Q$ offset that introduces an offset (error) into the calculated value of $\Psi_{\mathrm{e}}$. i.e. their use would underestimate the discharge capacity to the end point. Crucially, the desired information is available from $Q \mathrm{~d} V \mathrm{~d} Q^{-1}$ curves obtained in convectively cooled fast charging tests. These curves exhibited no stripping inflections and were obtained with near identical iSOC to that in the conductively cooled fast charging scenarios. This is clear in Figure 12a where there is only a very small horizontal offset between the start of convective (red) and conductive (other colors) curves. The case of $2.7 \mathrm{~mA} . \mathrm{cm}^{-2}$ charging was chosen because the temperature rise was the smallest of all convective fast charges, and thus most closely matches the conductively cooled cell temperature. Using this data, $\Psi_{\mathrm{e}}$ could be calculated for the case of $Q_{\text {stripped }}=0$, represented with the red star in Figure $12 \mathrm{~b}$. As a result, regression could be performed on conductively cooled data in the range $2.7 \mathrm{~mA} . \mathrm{cm}^{-2}$ to $9.1 \mathrm{~mA} . \mathrm{cm}^{-2}$ and on the convectively cooled data point (red star). Finally, calculation of $Q_{\text {stripped }}$ at $i=1.8 \mathrm{~mA} \cdot \mathrm{cm}^{-2}$ is possible by rearranging the regression model such that $Q_{\text {stripped }}=\frac{\Psi_{\mathrm{e}}-c}{m}$. The value calculated is given by the purple star. This interpolation produces an estimate of $Q_{\text {stripped }}=66 \mathrm{mAh}$ $(17.1 \mathrm{mg})$ in the case of $i=1.8 \mathrm{~mA} . \mathrm{cm}^{-2}$. This value is retrospectively given as the white-colored bar in Figure 10. It serves as demonstration of a novel method of increasing the sensitivity of the stripping quantification method, extending its application scope to lower levels of $\mathrm{Li}^{0}$ stripping.

The question naturally arises of when the conventional method of relying on inflection minima for $Q_{\text {stripped }}$ quantification fails. It is possible to estimate the threshold by considering the relationship between $Q_{\text {stripped }}$ and the number of real positive roots in the $Q \mathrm{~d}^{2} V \mathrm{~d} Q^{-2}$ inflection range. This relationship is linear $\left(\rho_{\mathrm{Q}_{\text {stripped }}, \xi}^{\mathrm{PCC}}=\right.$ $\left.-0.95, R^{2}=0.88\right)$. The threshold is defined by the $Q_{\text {stripped }}$ value at which one repeated real positive root exists and $Q \mathrm{~d}^{2} V \mathrm{~d} Q^{-2}$ touches but does not cross the horizontal axis. This threshold is represented in Figure $12 \mathrm{~b}$ as the gray box border. $Q_{\text {stripped }}$ values lying within the box are obtainable only with $\Psi_{\mathrm{e}}$ data. Those lying outside of the box are obtainable by conventional determination of inflection minima.

\section{Conclusions}

Through experimental testing of commercial graphite-NMC cells, deficiencies in state-of-the-art lithium plating identification and quantification methods were investigated and solutions proposed. Because iSOC and $T$ variations following fast charging strongly influence the cell terminal voltage, voltage vs. capacity $(V-Q)$ plots were shown not to be reliable for plating identification in the context of fast charging. DV analysis was instead shown to reliably identify stripping plateaus irrespective of iSOC and $T$. Increasing cooling system power did little to alleviate the problem because limiting the temperature rise exacerbates the formation of concentration gradients and causes iSOC to influence the voltage profile to a greater extent.

The application scope of the technique was shown to be far wider than previously believed. Unambiguous identification of stripping plateau end points with NC electrodes demonstrated that the PE contribution to cell potential need not be negligible for the identifica- tion of lithium plating. The technique can successfully be applied at temperatures as high as $0^{\circ} \mathrm{C}$ and with core cell temperatures even higher. The technique can therefore be employed under the conditions of EV fast charging when additional consideration is given. DV analysis and electrode microscopy validated the hypothesis that an absence of lithium stripping plateaus is not indicative of an absence of lithium plating. Therefore, the belief that no stripping plateau represents healthy, plating-free cell operation was shown to be a converse error. Traditionally, longer stripping plateaus have been considered to represent more dangerous scenarios with more lithium plating having occurred. However, the results highlight that the reverse may sometimes be true, since longer stripping plateaus represent good plating process reversibility. Dangerous processes such as lithium dendrite formation and earlier thermal runaway rely on the occurrence of irreversible plating. These dangerous processes are therefore inhibited when the plating process exhibits good reversibility, as indicated by the presence of a long stripping plateau.

The relationship between fast charging rate and chemical intercalation was investigated. The results suggest that lithium plating quantification without consideration for lithium chemically intercalated during CV phase charging causes underestimation of the plated quantity. The amount by which $\mathrm{Li}_{\text {plated }}$ is underestimated increases at the higher charging rates that render the plating both more likely and more extensive (dangerous). Moreover, the error involved in treating stripping quantification as plating quantification has been highlighted. The dependency of $Q_{\text {stripped }}$ on the discharge rate was investigated and further work is required to better understand the underlying mechanisms. Where lithium plating quantities are relatively small, $Q \mathrm{~d} V \mathrm{~d} Q^{-1}$ inflections were shown to not exhibit minima, limiting the sensitivity of the technique. $Q \mathrm{~d} V \mathrm{~d} Q^{-1}$ stripping inflection end points were demonstrated to contain valuable information and to exhibit a statistically significant correlation with $Q_{\text {stripped }}$. $\Psi_{\mathrm{e}}$ has therefore been suggested for estimation of $Q_{\text {stripped }}$ when $Q_{\text {stripped }}$ is so low in magnitude that $Q \mathrm{~d} V \mathrm{~d} Q^{-1}$ stripping inflections do not exhibit minima. As a result, the application window of the technique has been widened to include lower levels of lithium plating.

The field of in-situ lithium plating identification and quantification by the voltage plateau method remains underdeveloped. Valuable future work includes i) quantification of $\mathrm{Li}_{\text {chemical }}$. Novel plating quantification techniques, such as that presented in Ref. 31, could enable experimental quantification of $\mathrm{Li}_{\text {plated }}$ during charging. Differencing with respect to $\mathrm{Li}_{\text {plated }}$ as calculated by the voltage plateau method would enable $\mathrm{Li}_{\text {chemical }}$ estimation. ii) If $\mathrm{GoF}$ was to be improved between the calculated and experimental full cell DV profiles, then degradation mode quantification could be improved for cells MT1 and MT2, similar to that in Refs. 3, 34. The result could be compared with LLI quantities estimated in this work by the voltage plateau method, and the method's accuracy further studied. Lastly, further work is required to better understand the increases in capacities of some cells following charging and the influence on estimation of irreversible LLI owing to plating.

\section{Acknowledgments}

The authors are thankful for the financial support provided by the Engineering and Physical Sciences Research Council (EPSRC) under the Translational Energy Storage Diagnostics (TRENDS) project, part of the industrial strategy challenge fund EP/R020973/1. The authors are also thankful for the funding provided by the EPSRC and Jaguar Land Rover through an industrial CASE award. Finally, the authors thank Max Naylor-Marlow for his assistance performing SEM imaging and EDX.

\section{ORCID}

Ian D. Campbell (D) https://orcid.org/0000-0002-5465-6449

Mohamed Marzook (1) https://orcid.org/0000-0003-4430-7322 
Monica Marinescu (D https://orcid.org/0000-0003-1641-3371

Gregory J. Offer (D) https://orcid.org/0000-0003-1324-8366

\section{References}

1. V. Zinth, C. Von Lüders, M. Hofmann, J. Hattendorff, I. Buchberger, S. Erhard, J. Rebelo-Kornmeier, A. Jossen, and R. Gilles, Journal of Power Sources, 271, 152 (2014).

2. M. C. Smart and B. V. Ratnakumar, Journal of The Electrochemical Society, 158(4), A379 (2011)

3. D. Anseán, M. Dubarry, A. Devie, B. Y. Liaw, V. M. García, J. C. Viera, and M. González, Journal of Power Sources, 356, 36 (2017).

4. M. C. Smart, B. V. Ratnakumar, L. Whitcanack, K. Chin, M. Rodriguez, and S. Surampudi, IEEE Aerospace and Electronic Systems Magazine, 17(12), 16 (2002)

5. M. C. Smart, B. V. Ratnakumar, L. D. Whitcanack, K. B. Chin, S. Surampudi, H. Croft, D. Tice, and R. Staniewicz, Journal of Power Sources, 119-121, 349 (2003).

6. J. Fan and S. Tan, Journal of The Electrochemical Society, 153(6), A1081 (2006).

7. B. V. Ratnakumar and M. C. Smart. Lithium Plating and Lithium intercalation kinetics as a function of Electrolyte Composition. In Proceedings of the 216th ECS Meeting. The Electrochemical Society, 2009.

8. R. V. Bugga and M. C. Smart, Lithium Plating Behavior in Lithium-ion Cells. In ECS Transactions, 25, 241 (2010).

9. M. Petzl and M. A. Danzer, Journal of Power Sources, 254, 80 (2014).

10. M. A. Danzer, M. Bauer, S. Schindler, and M. Petzl, Detection and Characterization of Lithium Plating in Commercial Cells. In Advanced Automotive Battery Conference, Mainz, 2016.

11. X.-G. Yang, S. Ge, T. Liu, Y. Leng, and C.-Y. Wang, Journal of Power Sources, 395, 251 (2018)

12. S. F. Schuster, T. Bach, E. Fleder, J. Müller, M. Brand, G. Sextl, and A. Jossen, Journal of Energy Storage, 1, 44 (2015).

13. Q. Liu, C. Du, B. Shen, P. Zuo, X. Cheng, Y. Ma, G. Yin, and Y. Gao, RSC Advances, 6, 88683 (2016).

14. T. Waldmann, B. I. Hogg, and M. Wohlfahrt-Mehrens, Journal of Power Sources, 384, 107 (2018).

15. T. Waldmann and M. Wohlfahrt-Mehrens, Electrochimica Acta, 230, 454 (2017).

16. C. Uhlmann, J. Illig, M. Ender, R. Schuster, and E. Ivers-Tiffée, Journal of Power Sources, 279, 428 (2015).
17. S. Tippmann, D. Walper, L. Balboa, B. Spier, and W. G. Bessler, Journal of Power Sources, 252, 305 (2014)

18. M. Ecker, T. K. D. Tran, P. Dechent, S. Käbitz, A. Warnecke, and D. U. Sauer, Journal of the Electrochemical Society, 162(9), A1836 (2015).

19. J. Cannarella and C. B. Arnold, Journal of Power Sources, 245, 745 (2014).

20. J. Pokrzywa. SAE International standards work, including communication protocols and connectors, fast charge, batteries. In SAE International. SAE International, 2011.

21. Y. A. Cengel and A. J. Ghajar, Heat and Mass Transfer: Fundamentals \& Applications, McGraw-Hill, New York, fourth edition, 2010.

22. H. M. Dahn, A. J. Smith, J. C. Burns, D. A. Stevens, and J. R. Dahn, Journal of the Electrochemical Society, 159(9), A1405 (2012).

23. M. Winter, J. O. Besenhard, M. E. Spahr, and P. Novak, Advanced Materials, 10(10), 725 (1998).

24. D. Aurbach, B. Markovsky, I. Weissman, E. Levi, and Y. Ein-Eli, Electrochimica Acta, 45, 67 (1999).

25. T. Ohzuku, Y. Iwakoshi, and K. Sawai, Journal of The Electrochemical Society, 140(9), 2490 (1993)

26. C. Pastor-Fernández, K. Uddin, G. H. Chouchelamane, W. D. Widanage, and J. Marco, Journal of Power Sources, 360, 301 (2017).

27. M. S. Whittingham, Chemical Reviews, 104(10), 4271 (2004).

28. M. Tang, P. Albertus, and J. Newman, Journal of The Electrochemical Society, 156(5), A390 (2009).

29. T. Waldmann, J. B. Quinn, K. Richter, M. Kasper, A. Tost, A. Klein, and M. Wohlfahrt-Mehrens, Journal of The Electrochemical Society, 164(13), A3154 (2017).

30. B. Gyenes, D. A. Stevens, V. L. Chevrier, and J. R. Dahn, Journal of the Electrochemical Society, 162(3), A278 (2015).

31. J. Wandt, P. Jakes, J. Granwehr, R. A. Eichel, and H. A. Gasteiger, Materials Today, 21(3), 231 (2018)

32. C. von Lüders, V. Zinth, S. V. Erhard, P. J. Osswald, M. Hofmann, R. Gilles, and A. Jossen, Journal of Power Sources, 342, 17 (2017).

33. J. Kowal, J. Marscheider, D. Kober, and A. Gurlo, Detection of lithium plating by different methods. In Advanced Battery Conference 2018, Muenster, 2018.

34. C. R. Birkl, M. R. Roberts, E. McTurk, P. G. Bruce, and D. A. Howey, Journal of Power Sources, 341, 373 (2017).

35. D. Ren, K. Smith, D. Guo, X. Han, X. Feng, L. Lu, M. Ouyang, and J. Li, Journal of The Electrochemical Society, 165(10), A2167 (2018). 